$$
\begin{aligned}
& \text { ANL-6505 } \\
& \text { Engineering and Equipment } \\
& \text { (TID-4500, 17th Ed.) } \\
& \text { AEC Research and } \\
& \text { Development Report } \\
& (T / D-14789)
\end{aligned}
$$

ARGONNE NATIONAL LABORATORY

9700 South Cass Avenue

Argonne, Illinois

AN INVESTIGATION OF ENTHALPY DATA FOR WATER

AND WATER VAPOR IN THE CRITICAL REGION

by

E. S. Nowak and R. J. Grosh

Department of Mechanical Engineering

Purdue Research Foundation

Lafayette, Indiana.

September 1961

Technical Report No. 10

Atomic Energy Commission Contract AT(11-1)-1026

Argonne National Laboratory Subcontract 31-109-38-704

Operated by The University of Chicago

under

Contract W-31-109-eng-38 


\section{DISCLAIMER}

This report was prepared as an account of work sponsored by an agency of the United States Government. Neither the United States Government nor any agency Thereof, nor any of their employees, makes any warranty, express or implied, or assumes any legal liability or responsibility for the accuracy, completeness, or usefulness of any information, apparatus, product, or process disclosed, or represents that its use would not infringe privately owned rights. Reference herein to any specific commercial product, process, or service by trade name, trademark, manufacturer, or otherwise does not necessarily constitute or imply its endorsement, recommendation, or favoring by the United States Government or any agency thereof. The views and opinions of authors expressed herein do not necessarily state or reflect those of the United States Government or any agency thereof. 


\section{DISCLAIMER}

Portions of this document may be illegible in electronic image products. Images are produced from the best available original document. 


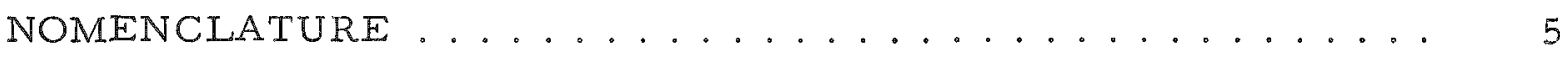

$\mathrm{ABSTRACT} \ldots \ldots \ldots \ldots \ldots \ldots \ldots$

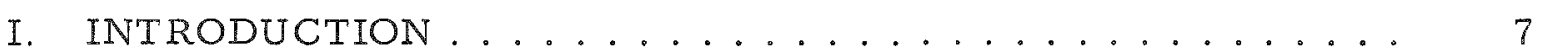

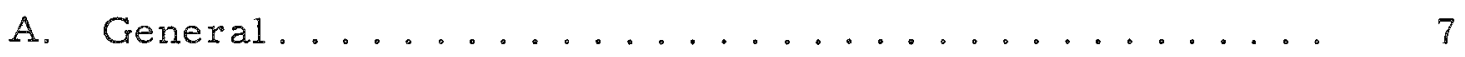

B. Some Remarks on Enthalpy............... 8

C. Reference Sources...................... 9

II. SMOOTHED VALUES OF ENTHALPY FOR SATURATED WATER

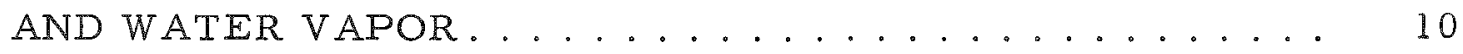

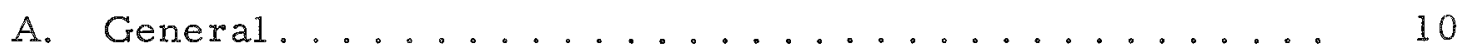

B. Basis of Various Steam Tables .............. 10

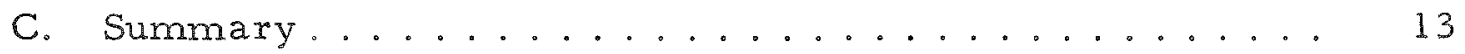

III. CALORIMETRIC AND VOLUMETRIC MEASUREMENTS OF SATURATED WATER AND WATER VAPOR.......... 14

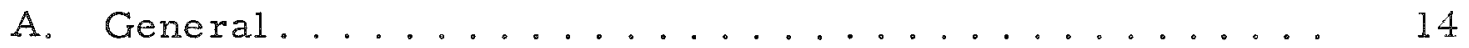

B. Calorimetric Measurements................ 14

1. Enthalpy of Vaporization Measurements by Koch. . . 14

2. Measurements of Jakob and Fritz........... 16

3. Measurements of Osborne et al............ 18

C. Volumetric Measurements ................ 21

1. Measurements of Eck................ 21

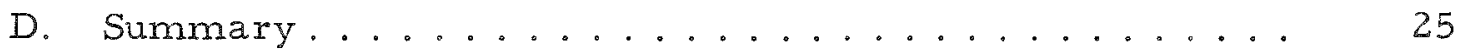

IV. MOST PROBABLE VALUES OF ENTHALPY FOR SATURATED

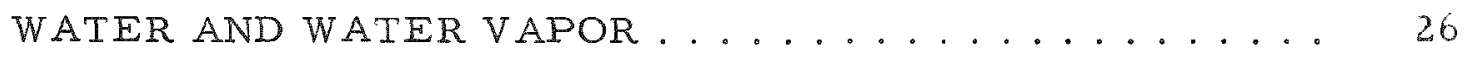

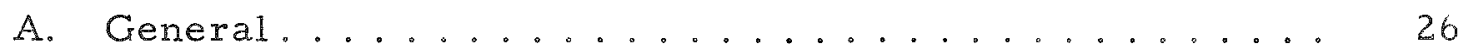

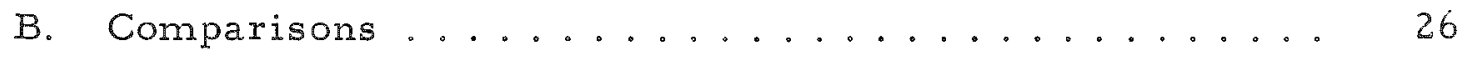

C. Most Probable Values of Enthalpy Along Saturation Line . 30

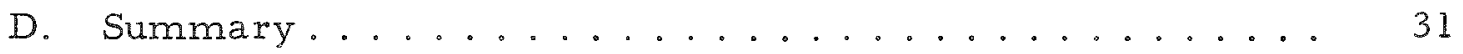


TABLE OF CONTENTS

$\underline{\text { Page }}$

V. SMOOTHED VALUES OF ENTHALPY FOR SUBCOOLED

WATER AND SUPERHEATED WATER VAPOR ....... 33

A. General......................... 33

B. Basis of Various Steam Tables and Other Reference

Sources......................... 33

1. Steam Tables .................. . . 33

2. Other Sources................... 35

C. Comparisons ......................... 35

D. Summary ........................... 37

VI. ENTHALPY MEASUREMENTS OF SUBCOOLED WATER AND SUPERHEATED WATER VAPOR. . . . . . . . 38

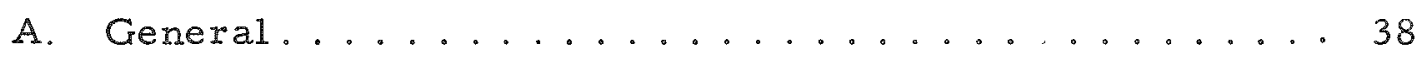

B. Theory of Measurement .............. 38

C. Enthalpy Measurements ................. 39

D. Summary ............................ 43

VII. ENTHALPY VALUES DERIVED IN THIS WORK . . . . . . 45

A. General........................... 45

B. Experimental Data Utilized............... 45

C. Theoretical Basis for the Method Used to Derive

Enthalpy Values . . . . . . . . . . . . . . 46

D. Derived Enthalpy Values................. 48

E. Summary........................... 51

VIII. INTERPOLATION TECHNIQUES AND SOME BOUNDARY CONDITIONS FOR A RELIABLE ENTHALPY FORMULATION. 52
A. General........................ 52
B. A Useful Interpolation Technique ............ 52
C. Consistency between Volumetric and Calorimetric Data . . 54
D. Summary. . . . . . . . . . . . . . . . . 57

ACKNOWLEDGEMENTS . . . . . . . . . . . . . . . 58

BIBLIOGRAPHY. . . . . . . . . . . . . . . . . 59 


\section{LIST OF TABLES}

No.

Title

$\underline{\text { Page }}$

1 A Enthalpy Difference Measurements on Subcooled Water by $\mathrm{Koch}(37) \ldots \ldots \ldots \ldots 15$

IB Enthalpy of Vaporization Measurements of $\mathrm{Koch}(37) \ldots 16$

$2 \gamma$ Measurements of Jakob and Eritz............ 17

3A a Measurements of Osborne et al............ 19

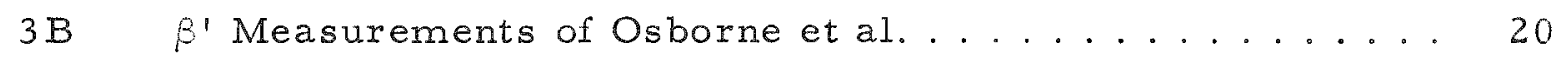

3C $\quad \gamma$ Measurements of Osborne et al............. 20

4 Volumetric Measurements of Eck Along the Saturation Line. 23

5 Volumetric Measurements of Riesenfield and Chang

Along the Saturation Line................ 25

6 Values of this Work for Enthalpy Along Liquid and Vapor Saturation Line.................. 31

$7 \quad$ Enthalpy Measurements of Havlicek and Miskovsky in the Critical Region. ................. 41

8 Enthalpy Measurements of Callendar and Egerton

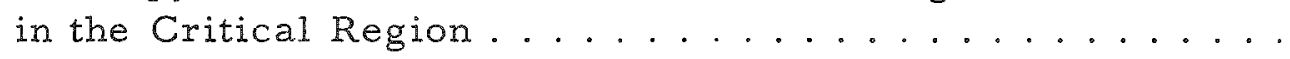




\section{LIST OF FIGURES}

No.

Title

Page

1 Smoothed Values for the Enthalpy of Saturated Water

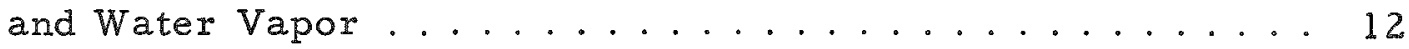

2 Variation of the Derivative, $\mathrm{dP}_{\mathrm{s}} / \mathrm{dT}$, with Temperature.... 27

3 Comparison Between Values Derived from Calorimetric and Volumetric Measurements Along the Liquid and Vapor Saturation Line ................. 28

$4 \quad$ Variation of $h_{f}-h_{f} V_{f} /\left(V_{g}-V_{f}\right)$ with Saturation Temperature. 30

5 Enthalpy Values of Various Steam Tables.......... 36

6 Values of Enthalpy Derived from Experimental Data. .... 49

7 Isenthalpic Curves for Water in the Critical Region...... 50

8 Variation of the Enthalpy Temperature Product with Enthalpy Along Isobars .................. 53

9 Variation of $F(T)$ with Temperature Along Three Isobars . . 55 


\section{NOMENCLATURE}

Thermodynamic Function

\begin{tabular}{|c|c|}
\hline $\mathrm{P}$ & absolute pressure, psia or $\mathrm{Kg} / \mathrm{cm}^{2}$ \\
\hline $\mathrm{V}$ & specific volume, $\mathrm{ft}^{3} / 1 \mathrm{~b}$ or $\mathrm{cm}^{3} / \mathrm{g}$ \\
\hline $\mathrm{T}$ & $\begin{array}{l}\text { absolute temperature either } \\
459.69+t,{ }^{\circ} \mathrm{R} \text { or } 273.16+t,{ }^{\circ} \mathrm{K}\end{array}$ \\
\hline $\mathrm{t}$ & temperature, ${ }^{\circ} \mathrm{F}$ or ${ }^{\circ} \mathrm{C}$ \\
\hline$U$ & internal energy per unit of mass \\
\hline$J$ & mechanical equivalent of heat \\
\hline $\mathrm{h} \mathrm{U}+\mathrm{PV} / \mathrm{J}$ & enthalpy \\
\hline S & entropy \\
\hline $\mathrm{C}_{\mathrm{P}_{\mathrm{W}}}$ & $\begin{array}{l}\text { specific heat at constant pressure of } \\
\text { subcooled water }\end{array}$ \\
\hline $\mathrm{C}_{\mathrm{p}}$ & $\begin{array}{l}\text { specific heat at constant pressure of } \\
\text { superheated vapor }\end{array}$ \\
\hline$E=1 / V(\partial V / \partial T)_{p}$ & $\begin{array}{l}\text { coefficient of volume expansion, }{ }^{\circ} \mathrm{R}^{-1} \\
\text { or }{ }^{\circ} \mathrm{K}^{-1}\end{array}$ \\
\hline
\end{tabular}

Thermal Quantities

$$
\begin{aligned}
& a \equiv h_{f}-\left(h_{f} V_{f}\right) /\left(V_{g}-V_{f}\right) \quad \text { quantity which may be derived from a } \\
& \text { special calorimetric experiment. } \\
& \beta^{\prime} \equiv\left(h_{f} V_{g}\right) /\left(V_{g}-V_{f}\right) \equiv \frac{T}{J} V_{f} \frac{d P_{s}}{d T} \\
& \text { quantity which may be derived from a } \\
& y \equiv h_{f}+\left(h_{f} V_{f}\right) /\left(V_{g}-V_{f}\right) \frac{T}{J} V_{g} \frac{d P_{s}}{d T} \\
& \text { quantity which may be derived from a }
\end{aligned}
$$

\section{Abbreviations}

$P-V-T$

pressure, specific volume and temperature

ht temperature enthalpy product 
JSME

VDI

TIC

Miscellaneous

Q

$Q_{\text {net }}$

Qloss

G

$\mathrm{G}_{\mathrm{C}}$

Gevap

$\mathrm{G}_{\mathrm{V}}$ or $\mathrm{G}_{\mathrm{W}}$

Subscripts

c

f

g

$f_{g}$

s

$m$

1

2
Japan Society of Mechanical Engineers

Verein Deutschen Ingenieure, Germany

The Third International Conference on Properties of Steam

rate of thermal energy addition or removal

net rate of thermal energy addition or removal

rate at which energy is lost to the outside

weight rate of fluid flow

weight rate of fluid being condensed

weight rate of fluid being evaporated weight rate of water vapor and water flow respectively

property at the critical point

property of saturated water

property of saturated water vapor

change in property between saturated

liquid state and saturated vapor state at the same temperature

property along the liquid - vapor

saturation line

mean condition

property at inlet of calorimeter

property at outlet of calorimeter 


\title{
AN INVESTIGATION OF ENTHALPY DATA FOR WATER AND WATER VAPOR IN THE CRITICAL REGION
}

by

E. S. Nowak and R. J. Grosh

\begin{abstract}
The available smoothed and experimental data for the enthalpy of water and water vapor in the region of pressures ranging from about 2850 to $4300 \mathrm{psia}$ ( 200 to $300 \mathrm{~kg} / \mathrm{cm}^{2}$ ) and for temperatures from 680 to $752^{\circ} \mathrm{F}\left(360\right.$ to $400^{\circ} \mathrm{C}$ ) has been compiled and analyzed. In general, good agreementwas found between the smoothed values of enthalpy of various steam tables. However there are significant deviations near the critical point and in the region of the inflection temperature on isobars of enthalpy versus temperature.

There has been only two independent investigations on the enthalpy of subcooled water and superheated water vapor. To rectify the paucity of data which results from this situation, the authors of this report derived enthalpy values from the available experimental results on the specific heat at constant pressure. The values soderived are in excellent accord with direct measurements of enthalpy. It was also possible to construct an isenthalpic diagram for water and water vapor in the critical region.
\end{abstract}

\section{CHAPTER I}

\section{INTRODUCTION}

\section{A. General}

This report is part of a broad program to investigate, compile, reanalyze and derive tentative but consistent values for the thermodynamic and transport properties of water and water vapor in the critical region. The property research program is being conducted at the Heat Transfer Laboratory of the School of Mechanical Engineering, Purdue University. It was initially intended to provide detailed and reliable information on the thermodynamic and transport properties for heat transfer investigations on water in the critical region. However, the scope of these studies has subsequently broadened. Important information has been and is being 
gained about various boundary conditions which must be satisfied by a fundamental equation of state. Furthermore some knowledge is being gained on the molecular structure in the so-called liquid and vapor phases of water substance above the critical point.

Earlier, studies were made of pressure - volume - temperature data $(44-47)^{*}$; the coefficient of volume expansion $(48)$; the specific heat at constant pressure $(49)$ and the thermal conductivity and dynamic viscosity. $(20,44)$

This present report gives information about the enthalpy of water and water vapor in that portion of the critical region encompassed by pressures of 2840 to $4270 \mathrm{psia}\left(200\right.$ to $\left.300 \mathrm{~kg} / \mathrm{cm}^{2}\right)$ and temperatures between 680 and $752^{\circ} \mathrm{F}\left(360\right.$ to $\left.400^{\circ} \mathrm{C}\right)$. From the results of this work it should be possible to derive consistent values for the specific heat at constant pressure and the Joule-Thompson coefficient.

The report which follows is divided into: Chapters II and III which give a compilation and comparison of the smoothed and experimental values for enthalpy at saturation conditions. Chapter IV which derives most probable values of enthalpy for the liquid and the vapor saturation conditions. Chapters V and VI which make a compilation and comparison of the smoothed and experimental values of enthalpy in the subcooled liquid and superheated water vapor regions. Chapter VII which describes the method. used in this work to derive reliable and consistent enthalpy values from specific heat measurements. Finally, Chapter VIII which gives a detailed account of certain boundary conditions which must be satisfied by a fundamental equation of state.

B. Some Remarks on Enthalpy, $h$

Enthalpy is a very important thermodynamic function. It is known to engineers abroad as the thermal potential or the total heat content. Enthalpy has been arbitrarily defined as the sum of the internal energy, $U$, and the pressure - specific volume product, PV, i.e.,

$$
\mathrm{h}=\mathrm{U}+\mathrm{PV} / \mathrm{J}
$$

where the factor $\mathrm{J}$ is the Mechanical Equivalent of Heat.

There are many factors and effects contributing to the internal energy of a fluid at rest. For example in a perfect gas the internal energy is simply equal to the sum of the translational kinetic energy possessed by each individual monatomic molecule. In the case of an imperfect or real gas the internal energy is equal to the sum of the translational kinetic energy, rotational kinetic energy, vibrational energy and intermolecular,

* Numbers in parentheses refer to references in the Bibliography. 
interatomic and interelectronic potential energies. A detailed knowledge of these effects will make it possible to understand more fully the theory of matter. It may be possible to at least obtain some knowledge of the magnitudes of some of the above effects from a detailed knowledge of the internal energy.

The second term contributing to enthalpy, the pressure - specific volume product, is also related to the internal energy. This may be deduced from the "Theorem of the Virial" by Clausius (see references 22 and 43). Clausius showed that the mean translational energy of a system of particles is equal to the sum of the virials of the external and intermolecular forces. The pressure - specific volume product, PV, is two thirds of the virial of the external forces. On the other hand, the virial of the intermolecular forces is related to the intermolecular potential energy. Thus the pressure - specific volume product, PV, may be considered as being related to the internal energy, even though the functional relationship may be quite complex.

The foregoing indicates that enthalpy may be considered as a function of internal energy. Its absolute value would be zero at that condition where all motion ceases and where there is no energy associated with position. Such a datum is fundamental and more research is needed to determine the zero point energy of water and water vapor.

In engineering applications the absolute values of enthalpy are seldom required. However enthalpy differences are of prime concern as they are encountered frequently. Thus at the First International Confer ence on Steam Tables (1) the enthalpy of saturated water at $0^{\circ} \mathrm{C}$ was arbitrarily assigned a value of zero. All steam tables sources cited here have adopted the above mentioned datum for the enthalpy. It must be emphasized, though, that in reality this is not the temperature where the enthalpy is actually zero and it is convenient only to consider it as a datum. Furthermore, at the datum where enthalpy is actually zero, the internal energy is zero. However, this is only of theoretical importance and therefore the datum as chosen in 1930 is justifiable from a practical point of view.

\section{Reference Sources}

The text by Dorsey(12) was an invaluable source of reference throughout the entire phases of this investigation as it quoted sources for the actual measurements. In this connection the survey report of Callendar(9) and the various steam tables were also of considerable help.

An attempt was made to study all of the research papers and reports on the enthalpy of water and water vapor which have been published since 1930. Furthermore the articles that have been written in other languages (notably Russian and German) have been translated. However, due to the pressure of time there may be some omissions. 
CHAPTER II

\section{SMOOTHED VALUES OF ENTHALPY FOR SATURATED WATER AND WATER VAPOR}

A. General

This chapter describes the basis of the smoothed enthalpy values of various steam tables and other sources for water and water vapor at saturation conditions. There is good agreement between most of the values in the interval 680 to $700^{\circ} \mathrm{F}\left(360\right.$ to $\left.371^{\circ} \mathrm{C}\right)$. However, the deviations between the values of various steam tables become marked on approach to the critical point $\left(P_{C}=3208\right.$ psia, $\left.V_{C}=0.0525 \mathrm{ft}^{3} / 1 \mathrm{~b}, t_{C}=705.5^{\circ} \mathrm{F}\right)$.

B. Basis of Various Steam Tables

In 1930 both Fiock(19) and Jakob(23) made comprehensive reviews of values for the enthalpy of saturated water and water vapor. The interested reader is referred to the above reviews since they give the status of the calorimetric properties of water and water vapor along the saturation line up to that time. The purpose of this section is to determine the basis and make a comparison of all steam table data appearing after the above reviews.

The basis of the values for saturated water and water vapor in the 1934 Skeletal Tables was not given explicitly. However it was stated(2) that the derived values were based on the available experimental data of German, Czechoslovakian, English and American investigators.

For temperature from about $680^{\circ} \mathrm{F}\left(360^{\circ} \mathrm{C}\right)$ to the critical point the values for the enthalpy of saturated water and water vapor in the Keenan and Keyes steam tables $(31)$ were derived by a graphical technique from the data of Osborne et al. (54) and the data adopted at the Third International Steam Table Conference.(2) Keenan and Keyes(31) stated that, "the region encompassing the critical point extending from a specific volume of $10 \mathrm{~cm}^{3} / \mathrm{g}$ on the vapor (saturation) side to a temperature of $680^{\circ} \mathrm{F}$ on the liquid (saturation) side, includes such rapidly changing derivatives that it has resisted formulation."

The formulations for enthalpy of saturated liquid and vapor derived at the National Bureau of Standards by Osborne et al. (54) formed the basis of many steam tables. In particular the above formulations were used to derive values in the tables of Dzung and Rohrbach, (13) Faxen, (18) Osborne et al. (56) and Vukalovich. $(68-70)$ Even though some of the Osborne et al. values exceed the tolerances adopted at the TIC, $(2)$ the various authors of the above steam tables did not consider that their derived values were in error. 
No basis was given for the values given in the 1939 Callendar steam tables. (8) However, in all probability they were derived from the values adopted at the $\mathrm{TIC}(2)$ and the formulations of Osborne et al. (54)

Leib $(41,42)$ stated that the values for enthalpy for saturated water in the tables of reference 40 were derived from the values adopted at the TIC. (2) Details of the graphical interpolation utilized were not given. Enthalpy values for saturated vapor were computed from an empirical equation of state based on the values adopted at the TIC. According to Leib the derived values do not have an uncertainty in excess of the tolerances adopted at the TIC. (2)

No basis was given for the enthalpy of saturated liquid and vapor in the successive tables of the VDI. $(39,60)$ However, the values in the latter differ from those in the former. Schmidt $(59)$ stated that, "in the neighborhood of the critical point the values under conditions of saturation have been altered slightly, in order to achieve a more even course of the saturation boundary curve." Thus it is not known whether these adjustments were made in an arbitrary manner or whether they were based on experimental data. It is thought by the authors of this work that the values in both of the VDI tables were derived from the results of Eck, (15) Jakob,(24) Koch (37) and the tables of TIC. (2)

No basis was given for the enthalpy values in the 1952 and 1958 steam tables of Timrot. $(65,66)$ It is thought that they might have been derived from the values of the TIC tables (2) and the experimental data of Eck,(15) Jakob,(24) Koch(37) and Osborne et al.(54) However this is a conjecture.

Keyes (32) derived values for the enthalpy of saturated water vapor from his semi-theoretical equation of state for saturation temperatures from 300 to $680^{\circ} \mathrm{F}\left(150\right.$ to $\left.360^{\circ} \mathrm{C}\right)$. He stated that, "the agreement of the computed values is satisfactory except at $350^{\circ} \mathrm{C}$ and $360^{\circ} \mathrm{C}$. The cause of the difference in enthalpy computed from measured the values at the latter temperature is not understood, particularly in view of the excellent accord between the computed and observed vapor pressure."

Figure 1 gives the values of various steam tables for water and water vapor for saturation temperatures ranging from $680^{\circ} \mathrm{F}$ to the critical temperature. A smooth curve was drawn through the Osborne et al. (54) data. One of the noteworthy features of the diagram is that there is excellent agreement between the values of all tables for the enthalpy of saturated liquid. This is not coincidental since probably all the compilers of various steam tables utilized either the smoothed or experimental values of Osborne et al. (54) 


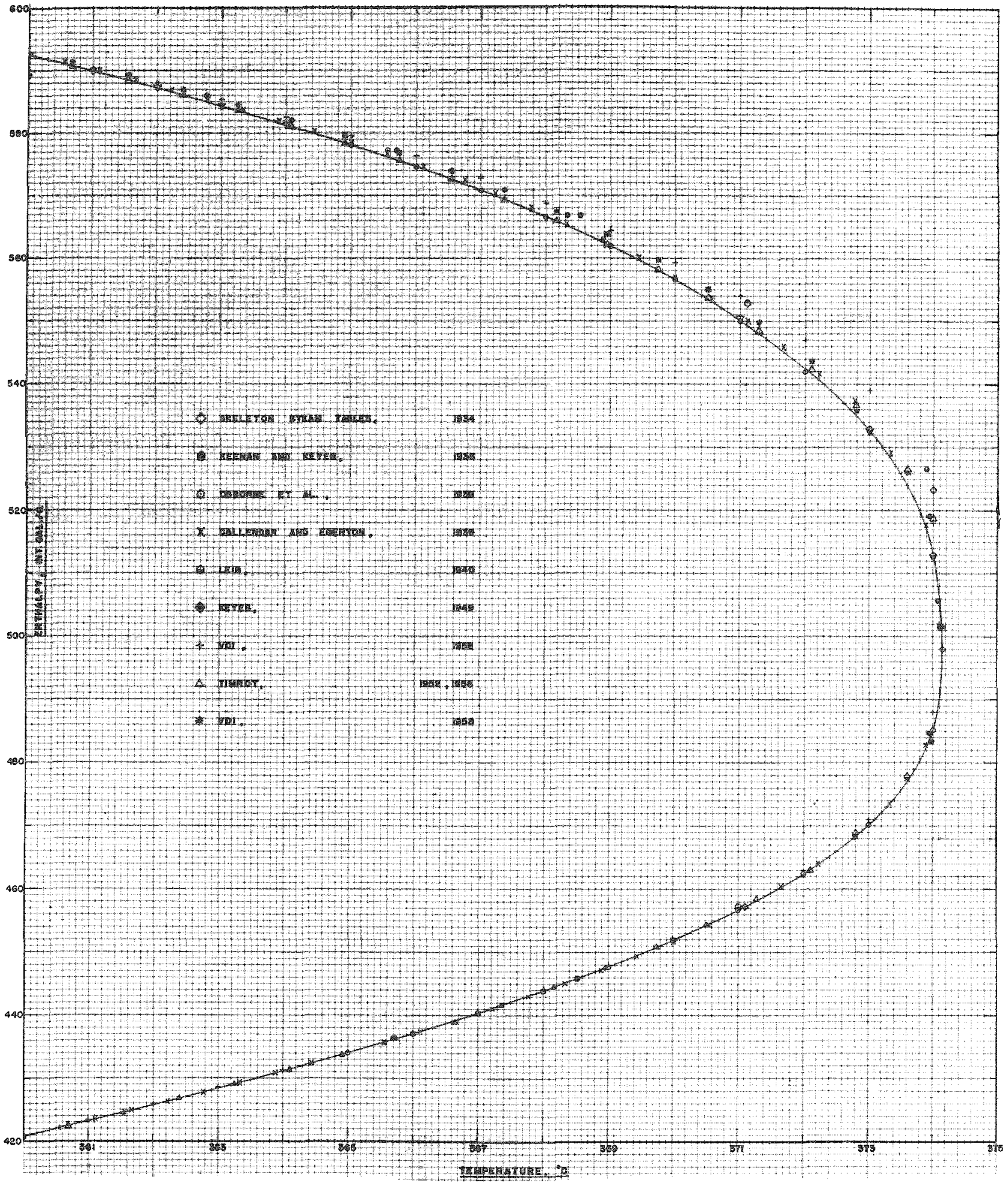

Fig. 1. Smoothed Values for the Enthalpy of Saturated Water and Water Vapor 
There is fair agreement between the various steam table data for the enthalpy of saturated vapor. All the values fall between the values of Osborne et al. (54) and those of the 1952 VDI steam tables. (39) Interestingly enough the values in the 1956 VDI tables (60) are in good agreement with the values of Osborne et al.(54)

In the region of a few degrees of the critical point there is a significant amount of disagreement between the various steam table values. In some cases the disagreement approaches five per cent. The next chapter analyzes the available 'experimental data' along the vapor and liquid saturation lines. From the analysis the reason for the above disagreement was found to be due to the disagreement between various 'experimental data.'

C. Summary

1. It appears that values of enthalpy for saturated water of all steam tables are based on the smoothed or experimental data of the U. S. Bureau of Standards.

2. To within one or two degrees of the critical point there is fair agreement between the enthalpy values (for saturated water) of various steam tables.

3. In the near vicinity of the critical temperature there are significant differences between the smoothed data. In some cases the deviations approached five per cent. 
CHAPTER III

\section{CALORIMETRIC AND VOLUMETRIC MEASUREMENTS OF SATURATED WATER AND WATER VAPOR}

\section{A. General}

A description is made of various direct measurements of the calorimetric and volumetric properties at saturation conditions.

The calorimetric experiments that have been carried out may be divided into two categories. The first type of experiment is the measurement of the latent heat of vaporization. The second type of experiment yields values which are related to the specific volume, enthalpy and the change of saturation pressure with temperature.

The volumetric experiments consisted of observing the corresponding saturation pressure and temperature at which a known quantity of saturated water or saturated water vapor completely occupied the known volume of a piezometer. The data from such measurements will be considered here as primary data. By means of the Clapeyron equation certain thermal quantities may be derived and compared directly with the values obtained from the previously mentioned calorimetric experiments.

\section{B. Calorimetric Measurements}

\section{Enthalpy of Vaporization Measurements by Koch (37)}

The enthalpy of vaporization is defined as the quantity of energy needed to change unit mass of saturated liquid to unit mass of saturated. water vapor under conditions of constant pressure and temperature.

The only direct measurements of the enthalpy of vaporization for water in the critical region are those by Koch. (37) To carry out these measurements Koch used the same apparatus which he designed and employed for his experiments on the specific heat of superheated water vapor and subcooled water. $(35,36)$

Koch evaluated the enthalpy of vaporization from the following experiment. As a known amount of water substance flowed through the calorimeter it received heat which (a) raised the temperature of subcooled water from $t_{1}$ to the saturation temperature $t_{s}$, (b) completely evaporated saturated water to saturated water vapor, (c) and finally superheated the water vapor to a temperature $t_{2}$ before allowing it to flow out of the calorimeter. The combined fluid flow and heat transfer proceeded at very nearly a constant pressure. 
If the heat losses* were insignificant compared to the total heat addition, the following energy balance may be written,

$$
Q / G=\int_{t_{1}}^{t_{s}} C_{p_{w}} d T+h_{f_{g}}+\int_{t_{s}}^{t_{2}} C_{p} d T
$$

where $G$ is the weight rate of flow and the other symbols have the meaning described in the nomenclature of this report. The first term on the right hand side of Equation (2) represents the energy necessary to raise the temperature of unit mass of subcooled water from $t_{1}$ to the saturation temperature. The second term represents the energy needed to change unit mass of saturated water to unit mass of saturated water vapor during constant pressure and temperature. The third term represents the energy required to superheat unit mass of water vapor from saturation conditions to a temperature $t_{2}$.

In the region of interest of this report, Koch evaluated by means of special experiments the energy necessary to raise the temperature of unit mass of subcooled water to saturation conditions. The results of these special experiments are given in Table $1 \mathrm{~A}$. Koch, on the other hand, utilized the results of his specific heat measurements on superheated water vapor (35) to evaluate the third term of Equation (2). 'Experimental values' for the enthalpy of vaporization, $\mathrm{hf}_{\mathrm{g}}$, were obtained by subtracting the above two terms from the measured values of $Q / G$.

Table $1 \mathrm{~A}$

\section{ENTHALPY DIFFERENCE MEASUREMENTS ON SUBCOOLED WATER BY KOCH(37)}

\begin{tabular}{|c|c|c|c|c|}
\hline $\begin{array}{c}\text { Pressure } \\
\text { P. } \mathrm{kg} / \mathrm{cm}^{2}\end{array}$ & $\begin{array}{c}\text { Saturation } \\
\text { Temp. } \\
\mathrm{t}_{\mathrm{s},}{ }^{\circ} \mathrm{C}\end{array}$ & $\begin{array}{c}\text { Entrance } \\
\text { Temp. of } \\
\text { Subcooled } \\
\text { Water } \\
\mathrm{t}_{1},{ }^{\circ} \mathrm{C}\end{array}$ & $\begin{array}{c}\text { Exit } \\
\text { Temp. of } \\
\text { Subcooled } \\
\text { Water } \\
\mathrm{t}_{2},{ }^{\circ} \mathrm{C}\end{array}$ & $\begin{array}{c}\text { Thermal } \\
\text { Energy Added } \\
\text { to Unit Mass } \\
\text { of Water } \\
\Delta \mathrm{h}, \mathrm{kcal} / \mathrm{kg}\end{array}$ \\
\hline \multirow{2}{*}{300} & 364.08 & 359.91 & 361.51 & 4.96 \\
& 359.89 & 362.93 & 9.97 \\
& & 363.89 & 14.0 \\
\hline
\end{tabular}

Koch's "measurements" for the enthalpy of vaporization are given in Table 1B. The maximum deviation from a mean value is five parts in one thousand. This agreement is noteworthy in view of the

*Koch's apparatus was designed such that the changes in the kinetic energy of fluid flow and elevation were insignificantly small compared to $Q$. 
experimental difficulties which must be surmounted. It also tends to indicate excellent internal accord between his specific heat measurements and his enthalpy of vaporization measurements.

Table $1 \mathrm{~B}$

ENTHALPY OF VAPORIZATION MEASUREMENTS OF KOCH(37)

\begin{tabular}{|c|c|c|c|c|c|}
\hline $\begin{array}{l}\text { Pressure } \\
\mathrm{P}, \mathrm{kg} / \mathrm{cm}^{2}\end{array}$ & $\begin{array}{c}\text { Mass } \\
\text { Elow } \\
\text { Rate } \\
\text { G, } \mathrm{kg} / \mathrm{hr}\end{array}$ & $\begin{array}{c}\text { Entrance } \\
\text { Temp. of } \\
\text { Subcooled } \\
\text { Water } \\
t_{1},{ }^{\circ} \mathrm{C}\end{array}$ & $\begin{array}{c}\text { Exit } \\
\text { Temp. of } \\
\text { Superheated } \\
\text { Water Vapor } \\
t_{2},{ }^{\circ} \mathrm{C}\end{array}$ & $\begin{array}{c}\text { Heat Added } \\
\text { to one } \mathrm{kg} \text { of } \\
\text { Water } \\
\text { Substance } \\
Q / \mathrm{G}, \mathrm{kcal} / \mathrm{kg}\end{array}$ & $\begin{array}{l}\text { Enthalpy of } \\
\text { Vaporization } \\
h_{f_{g}}, \mathrm{kcal} / \mathrm{kg}\end{array}$ \\
\hline 200 & $\begin{array}{l}1.6022 \\
1.0700 \\
1.6010 \\
1.6002 \\
1.6168 \\
1.0689 \\
1.6187 \\
1.6204 \\
1.6232 \\
1.6116 \\
1.6098\end{array}$ & $\begin{array}{l}361.26 \\
361.00 \\
361.21 \\
361.30 \\
361.24 \\
360.92 \\
361.21 \\
361.13 \\
361.15 \\
361.17 \\
361.1\end{array}$ & $\begin{array}{l}366.12 \\
366.18 \\
366.81 \\
367.56 \\
367.87 \\
368.05 \\
368.62 \\
369.40 \\
370.48 \\
372.10 \\
373.15\end{array}$ & $\begin{array}{l}172.9 \\
174.2 \\
176.3 \\
179.8 \\
180.9 \\
182.9 \\
184.3 \\
187.9 \\
192.0 \\
197.7 \\
200.8\end{array}$ & $\begin{array}{l}150.4 \\
150.8 \\
150.2 \\
150.5 \\
150.0 \\
150.2 \\
150.0 \\
150.2 \\
150.3 \\
150.4 \\
150.0\end{array}$ \\
\hline
\end{tabular}

2. Measurements by Jakob and Fritz $(24,25)$

The calorimetric experiments of Jakob and Fritz essentially consisted in principle of (i) evaporating air-free saturated water in a closed vessel and (ii) condensing a portion of the saturated water vapor in a second closed vessel at the same pressure as the initial vessel. Such measurements were painstakingly conducted for saturation temperatures ranging from 410 to $689^{\circ} \mathrm{F}\left(210\right.$ to $\left.365^{\circ} \mathrm{C}\right)$.

Under steady state heating conditions Jakob and Fritz correctly considered that the mass rate of saturated water being evaporated in the first vessel was somewhat greater than the mass rate of water vapor being condensed in the second vessel. The reason for this inequality is because a portion of the formed water vapor remains in the first vessel to occupy the volume originally taken up by a mass of saturated water prior to its evaporation.

Jakob and Fritz carefully corrected for the various heat losses and the superheating of the water and water vapor. The following heat balance may be written for a typical experiment

$$
Q_{\text {net }}=G_{\text {evap }} h_{f_{g}}
$$


where $G_{\text {evap }}$ is the weight $x$ ate at which saturated water is being evaporated in the first vessel. Jakob and Fritz did not measure Gevap but measured $G_{C}$, the rate at which condensate is formed in the second vessel. They showed, by means of a mass and an energy balance, the following relation to be valid:

$$
Q_{\text {net }}=G_{\text {evap }} h_{f_{g}}=G_{c}\left(h_{f} V_{g}\right) /\left(V_{g}-V_{f}\right)
$$

Since $Q_{\text {net }}$ and $G_{C}$ were measured quantities, values for $h_{f} V_{g} /\left(V_{g}-V_{f}\right)$ were computed $(24,25)$ and are given in Table 2 .* In view of the actual deviations between their "experimental data" it is reasonable to conclude that the error in the above quantities may be two per cent at $689^{\circ} \mathrm{F}\left(365^{\circ} \mathrm{C}\right)$. This amount of error probably led Jakob $(25)$ to state that "for temperatures in excess of $365^{\circ} \mathrm{C}$ the calorimetric method is no longer suitable as will be seen."

Table 2

MEASUREMENTS OF JAKOB AND FRITZ(24)

\begin{tabular}{|c|c|c|c|c|c|c|c|}
\hline $\begin{array}{c}\text { Saturation } \\
\text { Temp. } \\
t_{s},{ }^{\circ} \mathrm{C}\end{array}$ & $\begin{array}{c}\text { Rate } \\
\text { at which } \\
\text { Water Vapor } \\
\text { is Condensed } \\
\mathrm{G}_{\mathrm{C}} \text {, kg/hr }\end{array}$ & $\begin{array}{l}\text { Thermal Energy } \\
\text { Rate Needed to } \\
\text { Evaporate } \\
\text { Saturated Water } \\
\text { (corrected for } \\
\text { heat loss) } \\
\text { Qevap, kcallhr }\end{array}$ & $\frac{Q_{\text {evap }}}{\mathrm{G}_{\mathrm{C}}}$ & $\begin{array}{c}\text { Saturation } \\
\text { Temp. } \\
t_{\mathrm{s}},{ }^{\circ} \mathrm{C}\end{array}$ & $\begin{array}{c}\text { Rate } \\
\text { at which } \\
\text { Water Vapor } \\
\text { is Condensed } \\
\text { G. kg/hr }\end{array}$ & $\begin{array}{c}\text { Thermal Energy } \\
\text { Rate Needed to } \\
\text { Evaporate } \\
\text { Saturated Water } \\
\text { (corrected for } \\
\text { heat loss) } \\
\text { Qevap, kcalhr }\end{array}$ & $\frac{Q_{\text {evap }}}{G_{c}}$ \\
\hline 359.93 & 0.3802 & 89.87 & 236.38 & 364.88 & 0.1717 & 38.36 & 223.41 \\
\hline 359.97 & 0.1673 & 39.63 & 236.88 & 364.99 & 0.1649 & 35.92 & 217.83 \\
\hline 360.02 & 0.5586 & 132.23 & 236.72 & 365.00 & 0.5361 & 117.05 & 218.33 \\
\hline 359.98 & 0.1622 & 38.15 & 235.20 & 364.88 & 0.1530 & 33.68 & 220.13 \\
\hline 360.01 & 0.3813 & 88.87 & 233.07 & 364.95 & 0.5991 & 131.36 & 219.26 \\
\hline 360.04 & 0.2627 & 62.47 & 237.80 & 364.89 & 0.1521 & 33.10 & 217.62 \\
\hline 360.00 & 0.3755 & 88.73 & 236.30 & 364.88 & 0.1731 & 38.00 & 219.53 \\
\hline 360.02 & 0.1689 & 39.68 & 234.93 & 364.98 & 0.4750 & 105.62 & 222.35 \\
\hline 360.09 & 0.5573 & 131.48 & 235.92 & 364.96 & 0.1707 & 37.88 & 221.91 \\
\hline 360.02 & 0.5583 & 132.74 & 237.70 & 364.98 & 0.3090 & 67.39 & 218.09 \\
\hline 360.07 & 0.1676 & 39.58 & 236.16 & 364.93 & 0.5956 & 130.57 & 219.22 \\
\hline 360.08 & 0.3748 & 89.84 & 239.70 & 364.92 & 0.5968 & 131.63 & 220.56 \\
\hline 360.09 & 0.1611 & 38.72 & 240.35 & 364.98 & 0.1924 & 42.09 & 218.76 \\
\hline
\end{tabular}

Jakob and Fritz used the following procedure to obtain enthalpy of vaporization values from the measurements of Table 2 . By means of the Clapeyron equation they noted that

$$
Q_{\text {evap }} / G_{C}=h_{f} V_{g} /\left(V_{g}-V_{f}\right)=\frac{T}{J} V_{g} \frac{d P_{s}}{d T}
$$

They further recognized that the enthalpy of vaporization could be computed from the following equation

$$
h_{f_{g}}=\frac{Q_{\text {evap }}}{G_{C}}-\frac{T}{J} V_{f} \frac{d P_{s}}{d T}
$$

*Jakob and Fritz only give an average value for $h_{f_{g}} V_{g} /\left(V_{g}-v_{f}\right)$ at various temperatures. However individual values were computed from their measurements by the authors of this work by utilizing Equation (4). 
provided that values for $V_{f}$ and $d P_{S} / d T$ were available. Values of the enthalpy of vaporization were subsequently computed from Equation (6) by utilizing their measured values of $Q_{e v a p} / G_{C}$ and values of $V_{f}$ and $d P_{s} / d T$ of Smith and Keyes (64) and Osborne and Meyer(53) respectively.

The values of enthalpy of vaporization as obtained by Jakob and Fritz agree with the 'measured values' of Koch to within $0.5 \%$. By means of an empirical formulation, Jakob and Fritz extrapolated their values for $h_{f_{g}}$ to $701.6^{\circ} \mathrm{F}\left(372^{\circ} \mathrm{C}\right)$.

In the region of interest of this report enthalpy of vaporization values obtained from the empirical formulation may have uncertainty in them for the following reasons. It is known $(32,46)$ that above $680^{\circ} \mathrm{F}\left(360^{\circ} \mathrm{C}\right)$ the values of $V_{f}$ of Smith and Keyes $(64)$ are in error. Due to the error in $V_{f}$ and their measured values of $Q_{e v a p} / G_{C}$ considerable error could result especially upon empirical extrapolation.

It is not known to what extent the values of the enthalpy of vaporization as obtained from the Jakob and Fritz formulation have been incorporated in the 1937 and 1952 VDI tables, $(38,39)$ or even the tables of the TIC. (2)* However, if the formulation derived by Jakob and Fritz was used for temperatures above $689^{\circ} \mathrm{F}\left(365^{\circ} \mathrm{C}\right)$ considerable error would result and this would explain some of the error between the various steam table values (Figure 1).

3. Measurements of Osborne et al. (54)

Comprehensive measurements were made of three thermal quantities, which were related to various thermodynamic functions for saturated water and water vapor, at the U.S. Bureau of Standards by Osborne et al. (54) The experiments were designed by Osborne. (50) A brief description of the experiments follow:

(i) The changes in pressure and temperature were observed when heat was added to a fixed amount of saturated water and water vapor in a closed container.

(ii) The amount of saturated water vapor removed from a closed container was measured when heat was added to saturated water in the same container under conditions of constant temperature and pressure.

*Above $365^{\circ} \mathrm{C}$ the values of enthalpy of vaporization obtained from the Jakob and Fritz formulation(24) are almost identical with those in the 1937 and 1952 VDI tables $(38,39)$ and the TIC tables. (2) 
(iii) The amount of saturated water removed from a closed container was measured when heat was added to saturated water in the same container under conditions of constant temperature and pressure.

These three experiments, respectively, yielded values for three thermal quantities, $\alpha, \gamma, \beta^{\prime}$ defined as follows:

$$
\begin{aligned}
& \text { (a) } \alpha=h_{f}-h_{f} V_{f} /\left(V_{g}-V_{f}\right) \\
& \text { (b) } \gamma=h_{f} V_{g} /\left(V_{g}-V_{f}\right) \\
& \text { (c) } \beta^{\prime}=h_{f} V_{f} /\left(V_{g}-V_{f}\right)
\end{aligned}
$$

Thus the second experiment of Osborne et al. (54) is identical to that proposed by Jakob and Fritz.(24)

Experimental values for these three quantities, $\alpha, \beta, \gamma$, are given in Tables $3 \mathrm{~A}, 3 \mathrm{~B}$ and $3 \mathrm{C}$.

\begin{tabular}{|c|c|c|c|}
\hline $\begin{array}{l}310-300^{*} \\
\text { int. cal/gram }\end{array}$ & $\begin{array}{l}340-0330 \\
\text { int. cal/gram }\end{array}$ & $\begin{array}{c}300-325 \\
\text { int. cal/gram }\end{array}$ & $\begin{array}{l}360-350 \\
\text { int. cal gram }\end{array}$ \\
\hline 9.77701 & 9.69674 & 24.3476 & 9.67381 \\
\hline 9.76315 & 9.69913 & 24.3015 & 9.65493 \\
\hline 9.76793 & 9.68767 & 24.3712 & 9.67333 \\
\hline 9.76530 & 9.70678 & 24.3590 & 9.68360 \\
\hline 9.79206 & & 24.3760 & 9.59951 \\
\hline & & 24.3808 & 9.62483 \\
\hline$x_{320}-\alpha_{310}$ & $a_{350}-a_{340}$ & 24.3767 & 9.73042 \\
\hline int. cal/gram & int. cal/gram & $\begin{array}{l}24.3992 \\
24.3430\end{array}$ & $\begin{array}{l}9.71968 \\
9.69312\end{array}$ \\
\hline 9.74452 & 9.61695 & 24.3344 & \\
\hline 9.74643 & 9.64920 & & \\
\hline 9.74213 & 9.69483 & $-350-320$ & $\therefore 370-z_{360}$ \\
\hline 9.74548 & 9.67453 & 2nt.cal/gram & int. cal/gram \\
\hline 9.76268 & & 24.2210 & \\
\hline & & 24.2462 & 9.71131 \\
\hline$\alpha_{330}-\alpha_{320}$ & $\alpha_{350}-\alpha_{300}$ & 24.2066 & 9.64968 \\
\hline int. cal/gram & int. cal/gram & 24.2407 & 9.65780 \\
\hline & & 24.2334 & 9.65326 \\
\hline $9.709+0$ & 48.7821 & 24.3351 & 9.67572 \\
\hline 9.71394 & \pm 8.7768 & 24.1660 & 9.72971 \\
\hline 9.71323 & 48.7916 & 24.1471 & \\
\hline 9.71514 & 48.7281 & 24.2630 & \\
\hline 9.73304 & 18.6280 & 24.2518 & \\
\hline
\end{tabular}

Table $3 \mathrm{~A}$

: MEASUREMENTS OF OSBORNE et al. (54)

* Subscripts on $\alpha$ denote the temperature in degrees centigrade $\left({ }^{\circ} \mathrm{C}\right)$. 
Table 3B

$\beta^{\prime}$ MEASUREMENTS OF OSBORNE et al. (54)

\begin{tabular}{|c|c|c|c|}
\hline $\begin{array}{c}\text { Temperature } \\
\text { t, }{ }^{\circ} \mathrm{C}\end{array}$ & $\begin{array}{c}\beta^{\prime} \equiv\left(h_{f_{g}} V_{f}\right) /\left(V_{g}-V_{f}\right) \\
\beta^{\prime}, \text { int. cal /gram }\end{array}$ & $\begin{array}{c}\text { Temperature } \\
t,{ }^{\circ} \mathrm{C}\end{array}$ & $\begin{array}{c}\beta^{\prime} \equiv\left(h_{f} V_{f}\right) /\left(V_{g}-V_{f}\right) \\
\beta^{\prime}, \text { int. cal } / g \operatorname{gram}\end{array}$ \\
\hline 360 & $\begin{array}{l}64.4881 \\
64.4666 \\
64.4857\end{array}$ & 372 & $\begin{array}{l}94.5117 \\
94.4233 \\
94.5355 \\
94.3301\end{array}$ \\
\hline 365 & $\begin{array}{l}72.8205 \\
73.0475\end{array}$ & 373 & $\begin{array}{l}102.283 \\
102.053 \\
101.798\end{array}$ \\
\hline 370 & $\begin{array}{l}85.9355 \\
85.9379 \\
85.8209 \\
85.8615 \\
85.7827 \\
85.2428 \\
\end{array}$ & 373.5 & $\begin{array}{l}108.482 \\
109.2750 \\
107.777 \\
107.641 \\
106.693\end{array}$ \\
\hline 371 & 89.6479 & 374 & $\begin{array}{l}118.503 \\
117.672 \\
119.533 \\
123.993 \\
117.920 \\
125.343\end{array}$ \\
\hline
\end{tabular}

Table $3 \mathrm{C}$

$\gamma$ MEASUREMENTS OF OSBORNE et al. (54)

( $\gamma$ in int. cal $/ \mathrm{gram}$ )

\begin{tabular}{|c|c|c|c|c|c|c|}
\hline $360^{\circ} \mathrm{C}$ & $365^{\circ} \mathrm{C}$ & $370^{\circ} \mathrm{C}$ & $372^{\circ} \mathrm{C}$ & $373^{\circ} \mathrm{C}$ & $373.5^{\circ} \mathrm{C}$ & $374^{\circ} \mathrm{C}$ \\
\hline 236.185 & 217.212 & 191.388 & 174.883 & 163.173 & 153.192 & 137.313 \\
\hline 236.194 & 217.083 & 190.937 & 175.390 & 163.324 & 153.412 & 142.533 \\
\hline 236.302 & 217.301 & 191.364 & 174.671 & 163.687 & 163.226 & 140.971 \\
\hline 236.194 & 217.284 & 191.558 & 174.786 & 162.972 & 155.271 & 145.163 \\
\hline 236.158 & 217.238 & 191.446 & 175.887 & 163.161 & & 139.612 \\
\hline 236.268 & 217.169 & 192.033 & 177.246 & & & 135.785 \\
\hline 236.761 & 217.270 & 191.398 & 175.373 & & & 133.365 \\
\hline 236.285 & 217.301 & 191.501 & 175.734 & & & 143.023 \\
\hline 235.401 & 218.419 & 191.388 & 175.667 & & & \\
\hline 236.256 & 217.458 & 191.579 & 175.027 & & & \\
\hline 237.143 & 217.475 & 191.574 & 175.110 & & & \\
\hline 236.407 & 218.165 & 191.228 & 175.304 & & & \\
\hline 236.362 & 217.688 & 191.149 & 175.349 & & & \\
\hline 236.505 & 217.248 & 191.059 & 175.380 & & & \\
\hline 236.301 & 217.781 & 191.106 & 175.144 & & & \\
\hline 237.336 & & 191.075 & & & & \\
\hline 236.290 & & 191.068 & & & & \\
\hline 236.350 & & 191.221 & & & & \\
\hline 236.650 & & & & & & \\
\hline 236.562 & & & & & & \\
\hline 236.507 & & & & & & \\
\hline 236.264 & & & & & & \\
\hline 236.393 & & & & & & \\
\hline 236.335 & & & & & & \\
\hline 236.261 & & & & & & \\
\hline 236.457 & & & & & & \\
\hline
\end{tabular}


The accuracy of the $\beta^{\prime}$ and $\gamma$ measurements, with the exception of the region within a few degrees of the critical temperature, is probably one or two parts in one thousand. In the immediate vicinity of the critical temperature (within one or two degrees) the deviations approach some ten percent. The accuracy of the $\alpha$ measurements appear to be within a part in one thousand in the whole of the critical region.

Osborne et al. considered that their calorimetric measurements were satisfactory to within one degree of the critical temperature. How ever, they did state the need for additional data to be obtained by an entirely different experimental method for temperatures from $698^{\circ} \mathrm{F}\left(370^{\circ} \mathrm{C}\right)$ to the critical temperature.

Osborne et al. derived values for the specific volume, enthalpy and entropy of saturated water and water vapor from their measurements (Table 3). Their enthalpies of vaporization were in excellent agreement with those of Koch, (37) being entirely within two parts in one thousand. Furthermore their values of $\mathrm{h}_{\mathrm{g}}$ are between those of $\mathrm{Koch}(37)$ and $\mathrm{Jakob}$ and Fritz.(24) They are however in closer agreement with those of Koch. Osborne et al. considered that these larger differences between their data and those of Jakob and Fritz may be taken as evidence of the inherent difficulty connected with calorimetric measurements.

C. Volumetric Measurements

\section{Measurements of $\operatorname{Eck}_{\mathrm{ck}}(14,15)$}

Direct measurements of the specific volume of saturated water and water vapor were undertaken by $E_{c k}(14,15)$ for saturation temperatures ranging from $662^{\circ} \mathrm{F}\left(350^{\circ} \mathrm{C}\right)$ to the critical temperature. These measurements, in conjunction with values for $\mathrm{dP}_{\mathrm{s}} / \mathrm{dT}$, may be used to compute values for the following thermal quantities,

$$
\begin{aligned}
& \beta^{\prime}=\frac{T}{J} V_{f} \frac{d P_{S}}{d T} \\
& \gamma=\frac{T}{J} V_{g} \frac{d P_{S}}{d T}
\end{aligned}
$$

Apparently these measurements were first initiated and perhaps conducted under the direction of Jakob. Therefore, the apparatus used by Eck was probably that used by Jakob.*

*Jakob(25) stated that he made volumetric measurements at saturation conditions to check the measurements of H. L. Callendar (see reference 44). Eck, a former assistant of Jakob, carried on with the measurements. 
The method of measurement may be attributed to Cagniard de la Tour(5): A capillary of transparent material, usually quartz, is partially filled with air-free pure saturated water. Upon the addition of heat (care should be taken that observations are made during isothermal conditions) the following three observations are possible:

(a) The meniscus level rises as the temperature of the contents increases. At a certain temperature the capillary will be completely filled with saturated water. Thus the specific volume of saturated water may be taken to correspond to that latter temperature.

(b) The meniscus level gradually drops. At a certain temperature the whole of the capillary will be filled with saturated water vapor. Thus the specific volume of saturated vapor may be taken to correspond to that latter temperature.

(c) The meniscus rises slowly as the temperature of the contents increases. The critical point is that condition of pressure and temperature where the meniscus disappears at the mid-height of the capillary. The densities of water and steam have become equal and the specific volume at this condition is the critical specific volume.

The care and precision of Eck's investigations are noteworthy. For example, temperatures were measured with two platinum-platinum rhodium resistance thermometers to within $\pm 0.02^{\circ} \mathrm{C}$. Furthermore, during test conditions the capillary was in an almost isothermal enclosure since the largest temperature differences along the length of the capillary was less than $0.015^{\circ} \mathrm{C}$. If these measurements are correct it may be concluded that Eck succeeded in measuring temperatures accurately to within about $0.04^{\circ} \mathrm{C}$.

Eck used mercury to measure the volumes of the various capillaries. By weighing the capillaries with and without their charges of water, the mass of the latter was determined. Eck did not make any quantitative estimates about the accuracy of these determinations. However he did state that the above procedures produced "very accurate results."

The experimental values of specific volume along the vapor and liquid saturation line are given in Table 4 . In view of the care taken the error in the specific volume measurements is probably within a few parts in one thousand. Within a degree or so of the critical temperature the error is probably somewhat greater.

The enthalpies of vaporization derived by Eck are in close agreement with those derived by Jakob and Fritz. (24) This agreement, though noteworthy, may be partly explained by the fact that the measurements of Jakob and Fritz and those of Eck were obtained in the same laboratory. 
Table 4

VOLUMETRIC MEASUREMENTS OF ECK ALONG THE SATURATION LINE

\begin{tabular}{|c|c|c|c|}
\hline \multicolumn{2}{|c|}{ Saturated Water } & \multicolumn{2}{c|}{ Saturated Water Vapor } \\
\hline \multirow{2}{*}{$\begin{array}{c}\text { Temperature } \\
\text { t, }{ }^{\circ} \mathrm{C}\end{array}$} & $\begin{array}{c}\text { Specific } \\
\text { Volume } \\
\mathrm{V}_{\mathrm{f}}, \mathrm{cm}^{3} / \mathrm{g}\end{array}$ & $\begin{array}{c}\text { Temperature } \\
\mathrm{t},{ }^{\circ} \mathrm{C}\end{array}$ & $\begin{array}{c}\text { Specific } \\
\text { Volume } \\
\mathrm{V}_{\mathrm{g}}, \mathrm{cm}^{3} / \mathrm{g}\end{array}$ \\
\hline 349.43 & 1.739 & & \\
355.01 & 1.809 & 349.11 & 8.956 \\
357.54 & 1.851 & 352.93 & 8.254 \\
363.76 & 1.975 & 353.85 & 8.100 \\
364.38 & 1.988 & 354.43 & 7.899 \\
364.98 & 2.014 & 355.02 & 7.886 \\
366.15 & 2.048 & 358.42 & 7.253 \\
366.64 & 2.076 & 363.94 & 6.218 \\
370.23 & 2.224 & 365.78 & 5.851 \\
371.61 & 2.313 & 370.28 & 4.888 \\
371.80 & 2.332 & 372.25 & 4.367 \\
372.90 & 2.436 & 372.31 & 4.354 \\
373.82 & 2.594 & 373.78 & 3.781 \\
373.90 & 2.614 & 374.05 & 3.600 \\
374.01 & 2.654 & 374.17 & 3.422 \\
\hline
\end{tabular}

Eck's values for the critical pressure, specific volume and temperature differ somewhat from those accepted at present. (45) Eck's observations therefore will be considered in detail as it may be possible to establish reasons for the disagreement. The following values were observed for the critical constants $P C=225.51 \mathrm{~kg} / \mathrm{cm}^{2}, V c=3.07 \mathrm{~cm}^{3} / \mathrm{g}$, $t_{c}=374.23^{\circ} \mathrm{C}$.

The critical pressure found by Eck is in fair agreement with the value considered correct at present. (45) The critical temperature measured by Eck is about $0.08^{\circ} \mathrm{C}\left(0.15^{\circ} \mathrm{F}\right)$ higher than that obtained by Osborne et al. (54) While part of this discrepancy might be due to the uncertainty in Eck's measurement technique, this is unlikely as it appears to be as satisfactory as that utilized by Osborne et al. The more probable reason, is the uncertainty as to when the meniscus actually disappears. Eck found, for example, that at about $0.5^{\circ} \mathrm{C}$ below the critical temperature the meniscus is almost flat. Small bubbles could be seen rising in the liquid phase while small droplets could be seen falling on the meniscus from the vapor phase. With further increase of temperature the interplay of bubbles and droplets stop and the meniscus became completely flat. He observed that as soon as the thin dividing line had disappeared, a distinct 
broad zone appeared in its place. With further slight increase in temperature the zone disappeared and the contents of the capillary appeared completely homogenized. Eck considered the temperature at this condition to be the critical temperature.

In all probability the critical temperature is actually that point where interplay of steam bubbles and droplets ceases and also where the thin horizontal meniscus disappears. The broad zone that appears might be explained as that caused by excessive density gradients, i.e., slightly above, below and at the critical point, $\beta \equiv \frac{1}{V} \frac{\partial V}{\partial T} p$, is very large in magnitude. It should be recalled that there could be an error of $0.04^{\circ} \mathrm{C}$ in the temperature measurements. Thus a combination of the above factors could cause the $0.08^{\circ} \mathrm{C}$ difference between the values of Eck and Osborne et al.

It is also of interest to note that Eck's experiments were carried out with the temperature increasing at a rate of about $0.1^{\circ} \mathrm{C}$ per hour. This rate of increase is very small and at any instant one might unknowingly assume equilibrium conditions. However Wentorf and Boyd(72) found that in the critical region constant pressure is rapidly achieved, but that constancy of the fluid molecular structure requires five or more hours. If this is the case then another reason for the "high" critical temperature observed by Eck was that unknowingly he did not allow sufficient time for equilibrium to take place.

Eck did not obtain the value for the critical specific volume from direct observations. He considered that such observations at the critical point would be vitiated because of large density gradients. The critical specific volume was found by plotting $\left(V_{g}+V_{f}\right) / 2$ against temperature and extrapolating to the critical temperature. It should be pointed out that errors in the measurements of $V_{g}$ and $V_{f}$ increase upon approach to the critical point. Furthermore the quantity $\left(V_{g}+V_{f}\right) / 2$ is not linear with temperature. In view of these factors and also of the fact that the critical temperature, as determined by Eck, is likely to be too high, the value of Vc as found by Eck could be on the low side and could be in error by as much as five per cent.

At the end of this study the authors were directed to the experimental work undertaken by Riesenfeld and Chang.(57) Time did not permit a complete study of this work. However it was apparent that Riesenfeld and Chang did not use air-free samples of saturated water.

The measurements of Riesenfeld and Chang are given in Table 5. The data appear consistent to within about two per cent. Near the critical temperature the error may be as high as twenty per cent. 
Table 5

VOLUMETRIC MEASUREMENTS OF RIESENFELD AND CHANG ALONG THE SATURATION LINE*

\begin{tabular}{|c|c||c|c|}
\hline $\begin{array}{c}\text { Temperature } \\
\mathrm{t},{ }^{\circ} \mathrm{C}\end{array}$ & $\begin{array}{c}\text { Specific } \\
\text { Volume } \\
\mathrm{cm}^{3} / \mathrm{gram}\end{array}$ & $\begin{array}{c}\text { Temperature } \\
\mathrm{t},{ }^{\circ} \mathrm{C}\end{array}$ & $\begin{array}{c}\text { Specific } \\
\text { Volume } \\
\mathrm{cm}^{3} / \mathrm{gram}^{3}\end{array}$ \\
\hline 364.0 & 6.369 & 373.9 & 2.551 \\
373.1 & 4.098 & 373.7 & 2.513 \\
374.0 & 3.690 & 373.4 & 2.487 \\
374.0 & 3.472 & 372.9 & 2.444 \\
374.0 & 3.154 & 373.4 & 2.434 \\
374.3 & 3.106 & 371.8 & 2.273 \\
374.2 & 3.039 & 367.2 & 2.092 \\
374.2 & 2.915 & 366.5 & 2.079 \\
374.2 & 2.907 & 365.4 & 2.041 \\
374.2 & 2.825 & 365.4 & 2.037 \\
\hline
\end{tabular}

* The specific volume values proceed in regular order from saturated water vapor to saturated water.

D. Summary

1. Data derived by Jakob and Fritz are internally consistent with those derived by Eck. The results of Koch are in excellent agreement with those of Osborne et al.

2. The accuracy of individual measurements is good, being within five parts in one thousand. However, upon approach to the critical temperature the accuracy is not as good. For example, at a temperature of $705.2^{\circ} \mathrm{F}\left(374^{\circ} \mathrm{C}\right)$ the measurements disagree by about ten to twenty per cent. 


\section{CHAPTER IV}

\section{MOST PROBABLE VALUES OF ENTHALPY FOR SATURATED WATER AND WATER VAPOR}

\section{A. General}

In Chapters II and III inconsistencies were noted for both smoothed and 'measured' values of enthalpy. The purpose of this Chapter is to derive most probable values for the enthalpy from the measurements presented in Chapter III. It is realized that some measurements, particularly those of Osborne et al., are more precise than some of the others. Therefore more weight is attached to these particular measurements.

\section{B. Comparisons}

A comparison is given below for the values for $\beta^{\prime}$ and $\gamma$ obtained from the calorimetric measurement of Jakob and Fritz, Osborne et al. and the volumetric measurements of Riesenfeld and Chang. As stated previously precise values for $\beta^{\prime}$ and $\gamma$ may be derived from accurate values of $V_{f}, V_{g}$ and $\mathrm{dP}_{\mathrm{s}} / \mathrm{dT}$ by the following relations

$$
\begin{aligned}
& \beta^{\prime}=\frac{T}{J} V_{f} \frac{d P_{s}}{d T} \\
& \gamma=\frac{T}{J} V_{g} \frac{d P_{S}}{d T}
\end{aligned}
$$

Smith and Keyes (63) and Osborne and Meyers (53) showed that values of $\mathrm{dP}_{\mathrm{S}} / \mathrm{dT}$ obtained from their respective formulation for saturation pressure and temperature are in accord except within a few degrees of the critical temperature. For example, at the critical point the discord amounts to about one and one-half per cent.

The values of $\mathrm{dP}_{\mathrm{S}} / \mathrm{dT}$ used in this work, consequently, were those obtained by graphical differentiation of the vapor pressure measurements of Egerton and Callendar, (16) Osborne et al. (52) and Smith and Keyes.(63) A small scale reproduction of the curve constructed from such values of $\mathrm{dP}_{\mathrm{S}} / \mathrm{dT}$ is given in Figure 2 . These values of $\mathrm{dP}_{\mathrm{S}} / \mathrm{dT}$ were in good agreement with those derived by means of Osborne's and Meyer's saturation pressuretemperature formulation.

Figure 3 is a small scale reproduction of the curves constructed from the various $\beta^{\prime}$ and $\gamma$ values of Jakob and Fritz, (24) Osborne et al.,(54) Riesenfeld and Chang(57) and Eck. (14,15) The agreement between the various sets of data is good except in the region within about one degree of the critical point. Up to about $703.4^{\circ} \mathrm{F}\left(373^{\circ} \mathrm{C}\right)$ the values for $\beta^{\prime}$ and $\gamma$ derived by considering the above measurements as a single body of data are probably accurate to within at least ten parts in one thousand. 


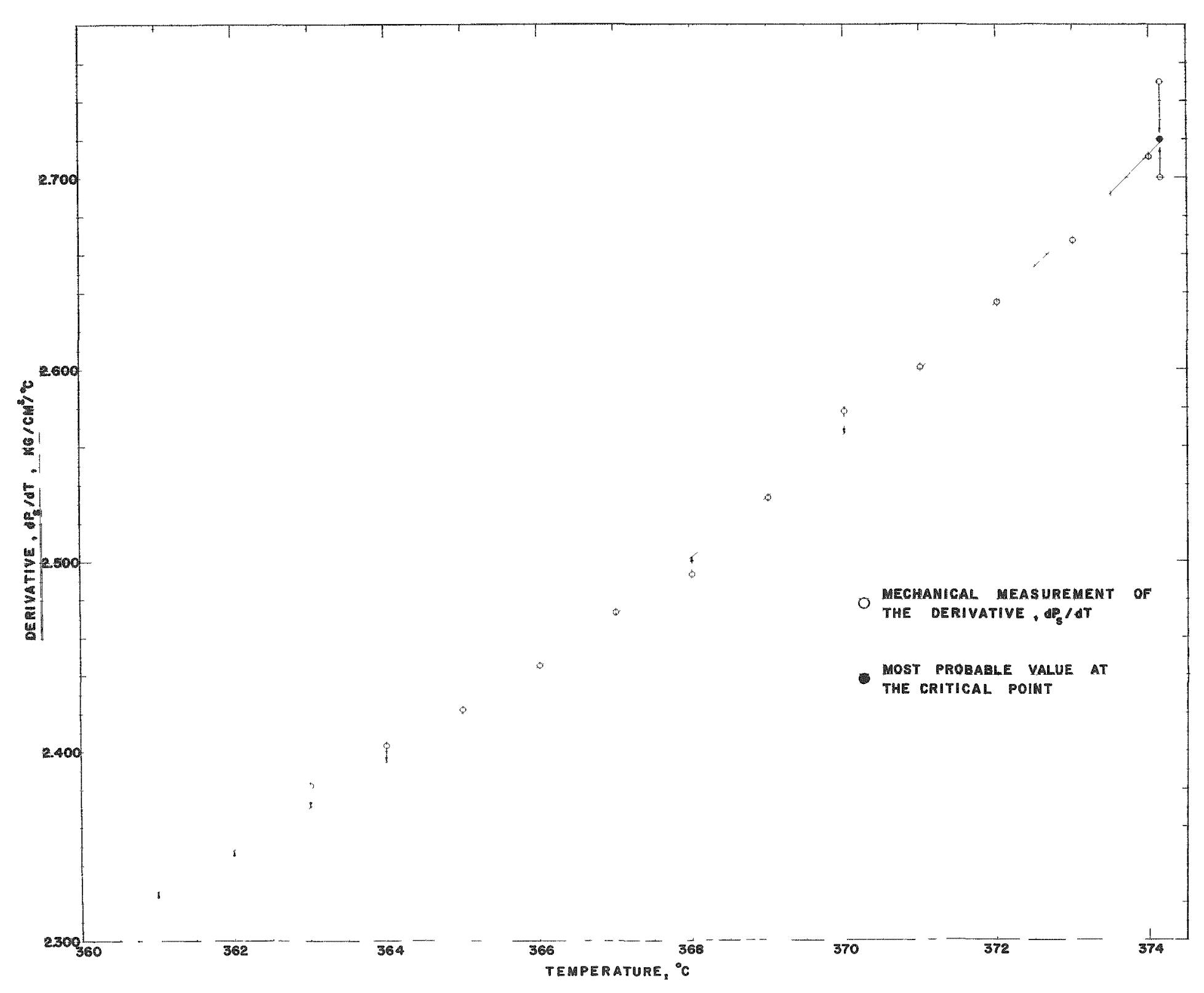

Fig. 2. Variation of the Derivatıve, d $P_{\mathrm{S}} / \mathrm{dT}$, with Temperature 


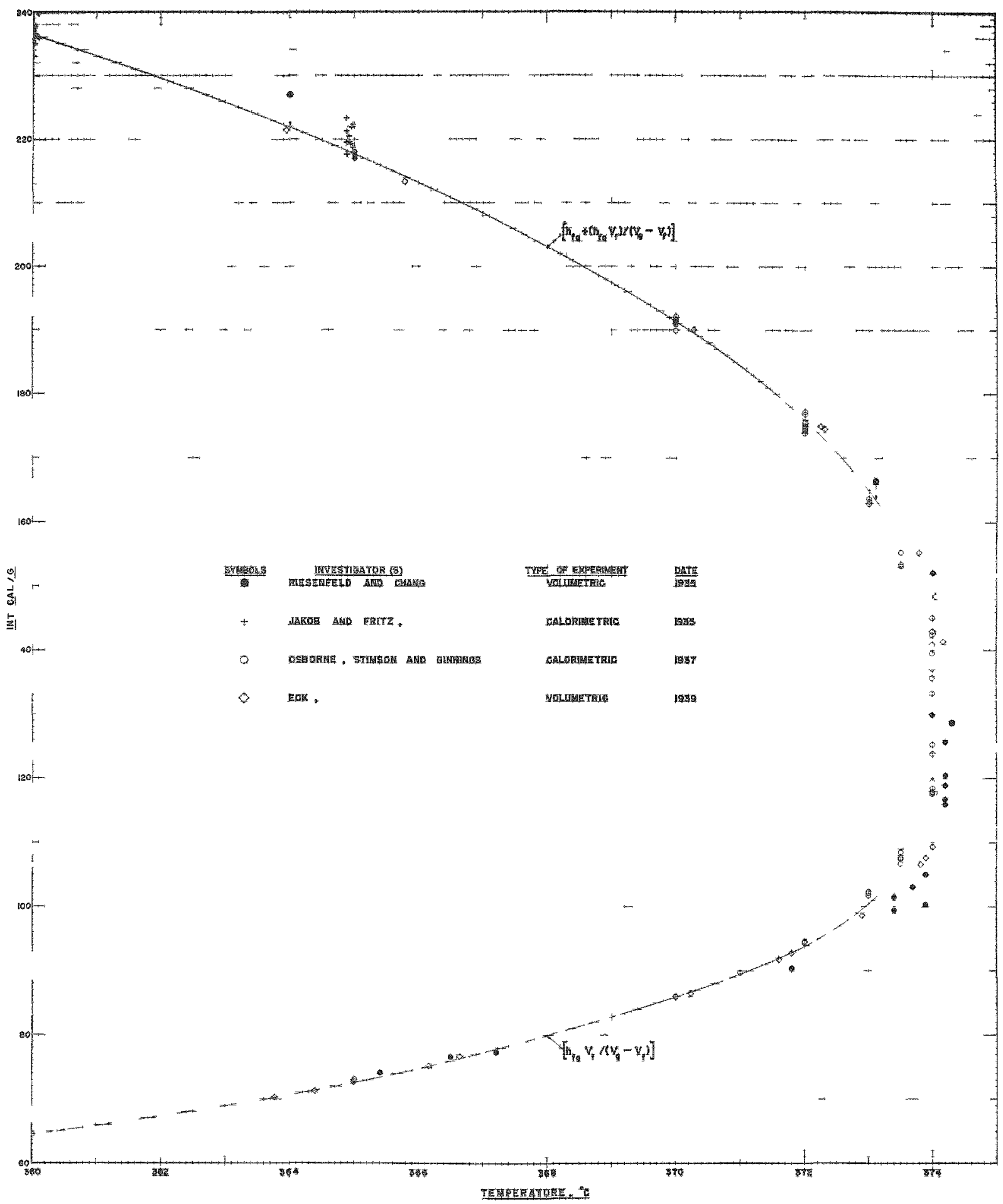

Fig. 3. Comparison between Values Derived from Calorimetric and Volumetric Measurements along the Liquid and Vapor Saturation Lines 
However for temperatures in excess of $703.4^{\circ} \mathrm{F}\left(373^{\circ} \mathrm{C}\right)$ deviations between individual measurements tend to approach some ten to twenty per cent.

It is known that Riesenfeld and Chang did not use air-free water samples. This might be the reason for some of the deviations in their data within a degree of the critical point. However, the values of Eck(15) and even the highly regarded data of Osborne et al. (54) show the same erratic trend. Figure 3 shows that new measurements must be undertaken with even more precision than that found in the investigations of Osborne et al. for temperatures within a degree of the critical temperature.

Apparently the only measurements for the quantity, $\alpha=h_{\mathfrak{f}}=$ $\left(h_{f} V_{f}\right) /\left(V_{g}-V_{f}\right)$, are those by Osborne et al. (54) On the basis of their measurements they developed the following empirical equation for the variation of $\alpha$ with temperature,

$$
\alpha=A_{0}+A_{1}(t-100)-A_{2}\left(t^{2}-100^{2}\right)-A_{3} \int_{100}^{t} 10^{-D t^{2}} d t
$$

where $A_{0}, A_{1}, A_{2}, A_{3}$ and $D$ are constants. Osborne et al. offered no explanation for such an empirical form.

By means of a cursory analysis it was thought that a less complex relation could be found. For example, the various measurements of $\alpha$ of Table $3 \mathrm{~A}$ with respective upper and lower measured limits are shown in Figure 4. It would appear that within the limits of accuracy the following straight line relationship reproduces the measurements satisfactorily in the region from $572^{\circ} \mathrm{F}\left(300^{\circ} \mathrm{C}\right)$ to the critical temperature*

$$
\alpha=h_{f}-h_{f} v_{f} /\left(V_{g}-V_{f}\right)=0.9713 t+6.630
$$

where

$h$ is the enthalpy, int. cal./gram

$\mathrm{V}$ is the specific volume, $\mathrm{cm}^{3} / \mathrm{gram}$

$t$ is the temperature, ${ }^{\circ} \mathrm{C}$.

It should be emphasized that the equation of Osborne et al. may yield more accurate values for $\mathrm{d} \alpha / \mathrm{d} t$ than that of this work. However the equation of this work does give values for $\alpha$ in the critical region which are highly accurate as it is representative of all of the $\alpha$ measurements.

* The base value chosen at $300^{\circ} \mathrm{C}$ was obtained from the measured results of Osborne et al. in the range 0 to $300^{\circ} \mathrm{C}$. 


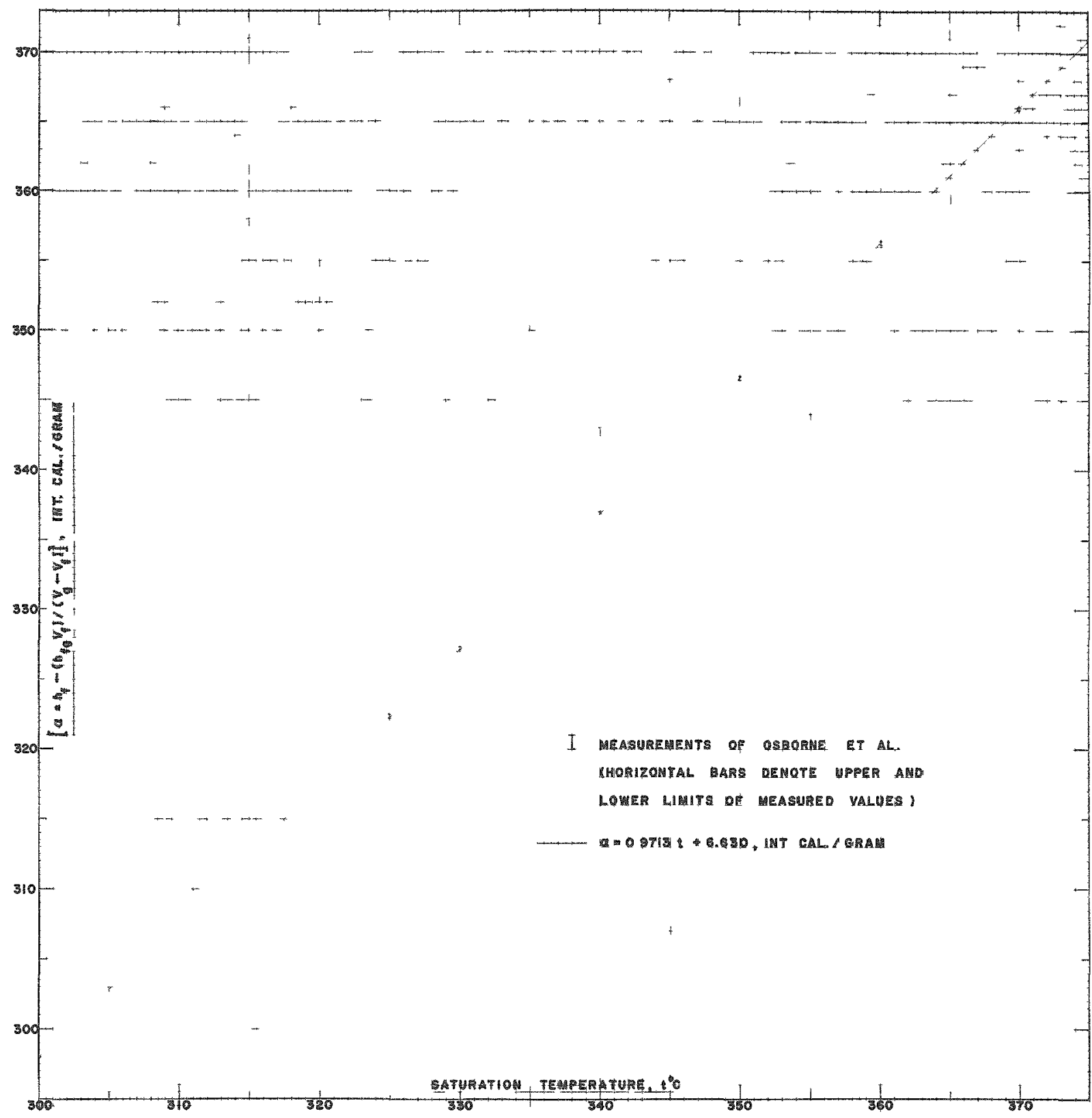

Fig. 4. Variation of, $h_{f}-\left(h_{f} g V_{f}\right) /\left(V_{g}-V_{f}\right)$, with Saturation Temperature C. Most Probable Values of Enthalpy Along Saturation Line

The enthalpy of saturated water and water vapor may be computed by means of the following equations:

$$
\begin{aligned}
& h_{f}=\alpha+\beta^{\prime} \\
& h_{g}=\alpha+\gamma
\end{aligned}
$$


By utilizing equations 13, 14, and 15 and the values of $\beta^{\prime}$ and $\gamma$ from the smoothed curve of Figure 3 values for enthalpy of saturated water and water vapor were derived. Such values are given in Table 6.

Table 6

VALUES OF THIS WORK FOR ENTHALPY ALONG LIQUID AND VAPOR SATURATION LINE

\begin{tabular}{|c|c|c|}
\hline $\begin{array}{c}\text { Saturation } \\
\text { Temperature, } \\
{ }^{\circ} \mathrm{C}\end{array}$ & $\begin{array}{c}\text { Enthalpy of } \\
\text { Saturated Liquid, } \\
\text { int. cal./g }\end{array}$ & $\begin{array}{c}\text { Enthalpy of } \\
\text { Saturated Vapor, } \\
\text { int. cal./g }\end{array}$ \\
\hline 360 & 420.75 & 592.81 \\
361 & 423.08 & 590.45 \\
362 & 425.61 & 587.85 \\
363 & 428.17 & 585.13 \\
364 & 430.81 & 582.18 \\
365 & 433.75 & 578.95 \\
366 & 436.93 & 575.35 \\
367 & 440.30 & 571.46 \\
368 & 443.98 & 567.09 \\
369 & 447.84 & 562.44 \\
370 & 452.01 & 556.51 \\
371 & 456.73 & 551.39 \\
372 & 461.77 & 543.95 \\
373 & 469.33 & 533.91 \\
374 & 484.10 & 515.55 \\
374.15 & 499.13 & 499.13 \\
\hline
\end{tabular}

It is very difficult to assess the accuracy of the values in Table 6 as there have been no direct measurements of enthalpy for either saturated water or water vapor. However, in view of Figures 3 and 4 it may be concluded that these are consistent with the available calorimetric and volumetric data.

D. Summary

1. Up to around $373^{\circ} \mathrm{C}\left(703.4^{\circ} \mathrm{F}\right)$ there is agreement between various measurements of $\beta^{\prime}$ and $\gamma$ to within around ten parts in one thousand.

2. The equation derived for $\alpha$ in this work, represents measurements to within a few parts in ten thousand. 
3. Most probable values of enthalpy along the liquid and vapor saturation curve have been presented in this report and are recommended for use.

4. The need for future analysis and measurements in the region within a degree of the initial region has been demonstrated. 


\section{CHAPTER V}

\section{SMOOTHED VALUES OF ENTHALPY FOR SUBCOOLED WATER AND SUPERHEATED WATER VAPOR}

\section{A. General}

This chapter contains an analysis and a graphical compilation of the values of enthalpy for subcooled water and superheated water vapor contained in the various steam tables. The smoothed enthalpy values of various steam tables were derived by graphical techniques from experimental values and the values adopted at the TIC. Recently however, Juza, (27-29) Kazavchinsky (30) and Keyes (32,33) have been carrying out extensive studies on a reliable equation of state. However, all of these works are not yet completed as several features of the various equations of state are being modified to secure better accord between computed and measured values of the various thermodynamic properties.

B. Basis of Various Steam Tables and other Reference Sources.

\section{Steam Tables.}

The pioneer work of Callendar on measurements of enthalpy $(6,7)$ will not be considered here. The reason for this is that his observations and conclusions about the critical point were not verified by subsequent careful experiments of Eck, (15) Jakob and Fritz, (24) Koch (34,37) and Osborne et al.(54) Callendar's conclusions and deductions are discussed in references $11,16,21,23,44,45$ and 49 . The interested reader should refer to these references as well as Callendar ${ }^{\natural}$ original research papers.

The basis for the enthalpy values adopted at the TIC are not known with certainty. However it is thought by the present authors that the TIC values are based on the measurements of Callendar and Egerton, (10) Havlicek and Miskovsky(21) and the computed values of Koch(38) and Davis and Keenan. (11) The TIC tables contain only three enthalpy values for the region considered here. Specifically, enthalpy values are given along the $752^{\circ} \mathrm{F}\left(400^{\circ} \mathrm{C}\right)$ isotherm at a pressure of 2850,3550 , and 4270 psia (200, 250 and $\left.300 \mathrm{~kg} / \mathrm{cm}^{2}\right)$.

The enthalpy values given in the Keenan and Keyes tables(3I) for superheated water vapor were computed by means of the following semi-graphical formulation

$$
h=m-\frac{n}{p}+\frac{1000 t}{p}+\delta
$$


where

$\mathrm{h}$ is in $\mathrm{k} \mathrm{cal} / \mathrm{kg}$

$\mathrm{p}$ is in $\mathrm{kg} / \mathrm{cm}^{2}$

$t$ is in ${ }^{\circ} \mathrm{C}$

$\delta$ is a graphical function of pressure and temperature

$m$ and $n$ are empirical constants.

This formulation is based on the adjusted measurements of Havlicek and Miskovsky. (21)* Keenan and Keyes stated that values of enthalpy and specific heat at constant pressure $\left[C_{p}=(\partial h / \partial T)_{p}\right]$ obtained from the formulation above the critical region were in satisfactory agreement with the measurements of Koch.

Havlicek and Miskovsky(21) present smoothed values of enthalpy along isotherms and isobars in the critical region. These were derived from their measurements of enthalpy and specific heat at constant pressure.

The enthalpy values in the 1939 Callendar steam tables $(8)$ are based wholly on the enthalpy measurements of Callendar and Egerton.(10) In the subcooled liquid region the enthalpy values were derived from the Keenan and Keyes steam tables.(31)

The enthalpy values in reference 40 were obtained from the semi-theoretical formulation derived by Leib. $(41,42)$ The constants were evaluated from the data adopted at the TIC.(2)

The basis for the 1937 and 1952 VDI tables $(38,39)$ is not clear. It is thought that they were derived by graphical techniques from experimental specific heat and enthalpy data of Koch(35) and Havlicek and Miskovsky.(21)

Values contained in the tables of Vukalovich(68-70) were de. rived by a graphical method from experimental measurements. Unfor tunately Vukalovich makes no specific mention of the primary data. utilized.

* The formulation was made consistently higher than the measured enthalpy values of Havlicek and Miskorsky by the amount of $1 \mathrm{cal} / \mathrm{gram}$. 
Graphical methods were used to derive the smoothed values in the 1952 and 1958 tables of Timrot. $(65,66)$ Timrot utilized the specific heat measurements of reference $(67)$ and the direct enthalpy measurements of Havlicek and Miskovsky.(21) Values of enthalpy in the 1956 VDI tables $(60)$ were taken directly from the 1952 Timrot tables. (65)

In the subcritical region values in the Faxen tables were obtained from Juza's formulation. (21) No basis is given for the values in the critical region.

\section{Other Sources.}

It was stated at the outset that a considerable amount of time has been devoted in an attempt to deduce an analytical equation. Some of the more prominent of these investigations will be discussed.

Keyes in 1949 derived an equation of state(33) which was based wholly on his P-V-T measurements. (32) By means of this equation, enthalpy values were computed in the superheated vapor region. The lower limit of applicability of the equation of state apparently is $752^{\circ} \mathrm{F}\left(400^{\circ} \mathrm{C}\right)$. Evidently this equation of state has not been tested for enthalpy below this temperature in the supercritical region. Keyes is still very actively engaged in such investigations.

In 1958 Kazavchinsky(30) computed values for the enthalpy of superheated vapor. The exact basis of his empirical equation of state is not known to the present authors of this report. Evidently the lower limit of application of their equation in the supercritical region is $752^{\circ} \mathrm{F}\left(400^{\circ} \mathrm{C}\right)$.

The analytical investigations conducted by Juza on an equation of state are noteworthy. Though not yet completed, the accord between values obtained from his equation of state $(27-29)$ and those derived from specific heat measurements is excellent. The greatest discord occurs in the region of maximum specific heat and amounts to some four to five $\mathrm{k} \mathrm{cal} / \mathrm{kg}$. This corresponds to approximately one per cent error in the enthalpy. Juza's equations will not be given here because they are in the process of modification and they will be considered in a subsequent study performed by the present authors of this report.

\section{Comparisons}

The enthalpy values of the various steam tables for subcooled water and superheated water vapox are presented in Figure 5. The solid lines were constructed according to the values of the 1952 and 1958 Timrot tables. The broken lines were constructed according to the derived values of Havlicek and Miskovsky.(21) 


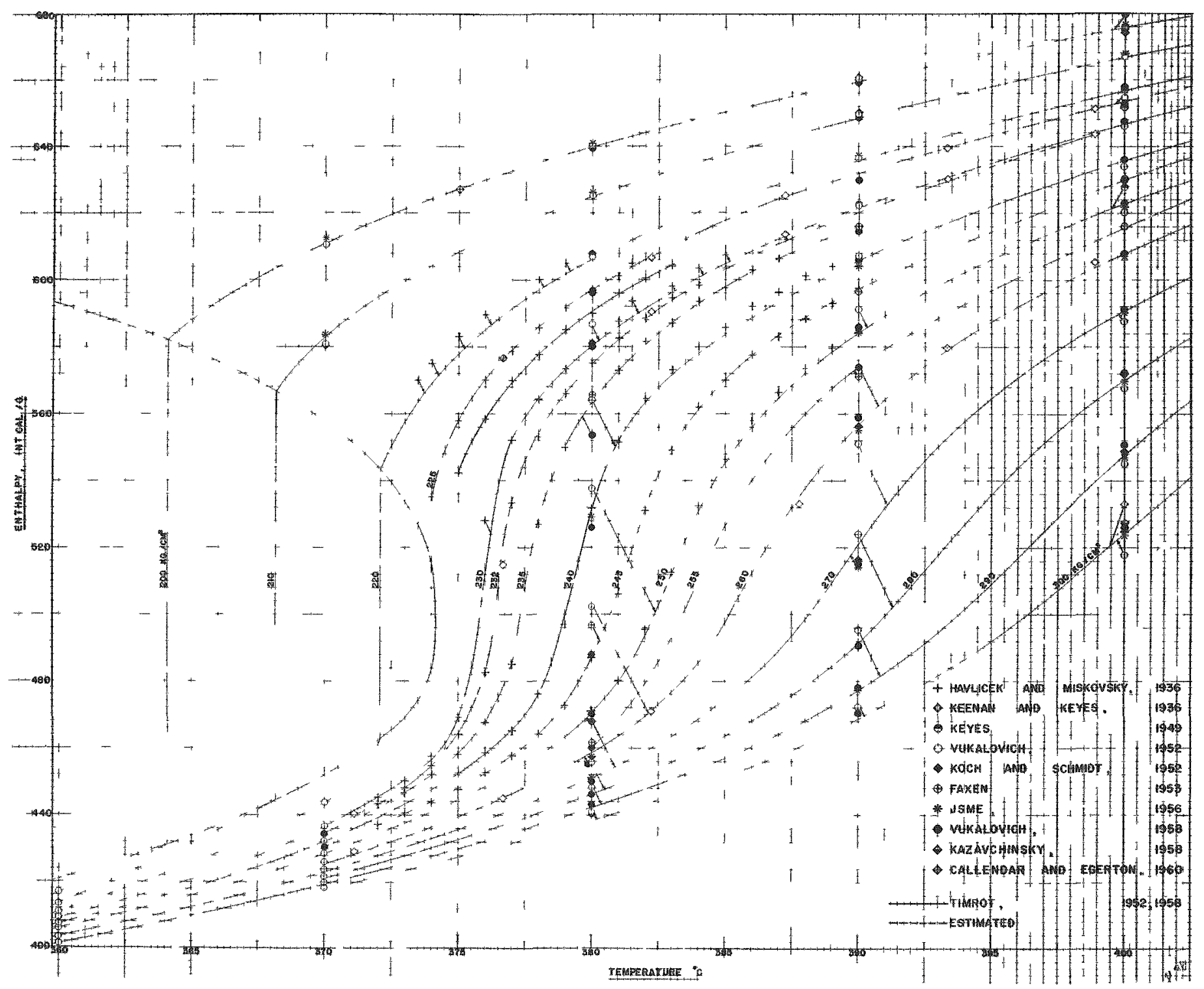

Fig. 5. Enthalpy Values of Various Steam Tables 
In general there is fair agreement between the values of various tables. The exceptions to this are in the regions of inflection along various isobars and the values of the 1952 Vukalovich tables. No details were given by Vukalovich about the graphical methods used to derive enthalpy values.

The maximum deviation of the 1952 Vukalovich data from the Timrot data is $140 \mathrm{~B} / 1 \mathrm{~b}(70 \mathrm{k} \mathrm{cal} / \mathrm{kg})$. This is many times in excess of experimental uncertainty. The accord between the 1958 Vukalovich data and the Timrot data, on the other hand, is fair. Vukalovich in his later steam tables offers no explanation for the previous discrepancies.

D. Summary

1. All steam table data were derived by graphical methods from the various experimental specific heat and enthalpy measurements.

2. In general there is good agreement between the values of all steam tables. It was found that the 1958 enthalpy values of Vukalovich were in fair agreement with those of Timrot's tables. No reason was given by Vukalovich for the previous discord.

3. Extensive analytical programs on an equation of state are still underway in Russia, Czechoslovakia and America. 


\section{CHAPTER VI}

\section{ENTHALPY MEASUREMENTS OF SUBCOOLED WATER AND SUPERHEATED WATER VAPOR}

\section{A. General}

Direct measurements on the enthalpy of subcooled water and superheated water vapor have only been made by Havlicek and Miskovsky (21) and Callendar and Egerton.(10) These measurements have formed the basis of enthalpy values of various steam tables. Even though the values of Callendar and Egerton are 1 to $3 \mathrm{cal} / \mathrm{gram}$ lower than the values of Havlicek and Miskovsky it is not considered significant as such deviations are entirely within experimental error. Detals of these measurements and experimental techniques follow.

B. Theory of Method of Measurement

The measurements of enthalpy have been carried out by the socalled continuous flow condenser method. This method essentially consists of measuring the pressure and temperature of superheated vapor or subcooled water in a high pressure insulated chamber. The contents in the high pressure chamber were allowed to expand (without any change in enthalpy) into a low pressure condenser. The rise in temperature and flow rate of the condenser cooling water required to completely condense the water vapor were noted.

If no heat transfer occurred between the high and low pressure sections and if there were no external work and energy associated with the velocity of fluid flow, the following heat balance results

$$
m_{v} h=\int_{T_{1}}^{T_{2}} m_{W} C_{p_{W}} d T+\int_{0}^{T_{3}} m_{V} C_{p_{W}} d T
$$

where

\footnotetext{
$m_{V}$ is the mass rate of water vapor flow from the high pressure chamber.

$\mathrm{m}_{\mathrm{w}}$ is the mass rate of cooling water in the low pressure condenser.

$\mathrm{C}_{\mathrm{p}_{\mathrm{W}}}$ specific heat of subcooled water

$T_{1}, T_{2}$ initial and final temperatures of the cooling water.

$T_{3}$ is the final temperature of the condensate.
} 
In actual fact heat losses and energies associated with the flow of superheated water vapor and subcooled water occur. To allow for these the equation for the heat balance is written as

$$
\begin{gathered}
m_{\mathrm{V}} \mathrm{h}+\frac{\mathrm{m}_{\mathrm{v}} \mathrm{u}_{1}^{2}}{2 \mathrm{~g}}=\int_{\mathrm{T}_{1}}^{\mathrm{T}_{2}} \mathrm{~m}_{\mathrm{w}} \mathrm{c}_{\mathrm{p}_{\mathrm{W}}} \mathrm{dT}+\int_{0}^{\mathrm{T}_{3}} \mathrm{~m}_{\mathrm{V}} \mathrm{C}_{\mathrm{p}_{\mathrm{W}}} \mathrm{dT} \\
+\frac{\mathrm{m}_{\mathrm{v}} \mathrm{u}_{2}^{2}}{2 \mathrm{~g}}+Q_{\text {los }} .
\end{gathered}
$$

In the experiments of Havlicek and Miskovsky and Callendar and Egerton the energy of flow $\left[\left(\mathrm{m}_{\mathrm{V}} \mathrm{u}_{1}{ }^{2} / 2 \mathrm{~g}\right)\right.$ and $\left.\left(\mathrm{m}_{\mathrm{V}} \mathrm{u}_{2}{ }^{2} / 2 \mathrm{~g}\right)\right]$ was insignificant compared with the enthalpy. Thus the heat balance may be written

$$
m_{v} h=\int_{T_{1}}^{T_{2}} m_{W} C_{p_{W}} d T+\int_{0}^{T_{3}} m_{v} C_{p_{W}} d T+Q_{\text {loss }} .
$$

It may be shown however that

$$
\int_{T_{1}}^{T_{2}} m_{W} C_{p_{W}} d T+\int_{0}^{T_{3}} m_{V} c_{p_{W}} d T=m_{V} h_{2}
$$

where $h_{2}$ is the enthalpy of the low pressure water vapor just prior to entering the condenser or heat exchanger.

Both Havlicek and Miskovsky, and Callendar and Egerton were concerned about the heat loss. The heat loss, if uncorrected, would have introduced a maximum error of about one per cent in their measured enthalpy values.

\section{Enthalpy Measurements}

Havlicek and Miskovsky made measurements of enthalpy at over one hundred pressure and temperature conditions between 14.22 and $5700 \mathrm{psia}$ ( 1 and $400 \mathrm{~kg} / \mathrm{cm}^{2}$ ), and temperatures between 68 and $1022^{\circ} \mathrm{F}$ $\left(20\right.$ and $\left.550^{\circ} \mathrm{C}\right)$. They stated that the enthalpy was measured at least six times at one individual pressure and temperature condition. One measurement of enthalpy could be carried out in one day and consequently 600 man days were devoted solely to the measurement of enthalpy.

Havlicek and Miskovsky utilized precision platinum resistance thermometers to measure the temperature of the contents in the high pressure chamber. These thermometers were periodically calibrated at the Physikalische Reischanatalt at Berlin. Precautions were taken 
to shield the thermometers against radiation. They considered that the temperature of the contents in the high pressure chamber were measured accurately to within $0.1^{\circ} \mathrm{C}$. Precision mercury thermometers were utilized to measure the temperature of the low pressure condensate and the cooling water to within $0.02^{\circ} \mathrm{C}$.

Havlicek and Miskovsky stated that the measurements of pressure in the high and low pressure chambers were their most accurate determinations. For example, a pressure of $400 \mathrm{~kg} / \mathrm{cm}^{2}$ could be measured accurately to within $0.1 \mathrm{~kg} / \mathrm{cm}^{2}$. The condensate and weight $\mathrm{r}$ ate of flow of cooling water was measured accurately to within $0.025 \%$.

They utilized the specific heat values of subcooled water that were measured by Osborne et al.(51) Thus knowing $\mathrm{m}_{\mathrm{W}}, \mathrm{m}_{\mathrm{V}}$, and temperature of the cooling water at exit and inlet and that of the condensate a value for $m_{\mathrm{V}} h_{2}$ was obtained. They estimate that the error introduced in $m_{V} h_{2}$ as a result of the error in $\mathrm{C}_{\mathrm{p}_{\mathrm{w}}}$ was only $0.05 \%$.

The maximum heat loss that occurred in the measurements of Havlicek and Miskovsky was around one per cent. Special calibration tests were made to evaluate the heat loss. By means of these tests the total heat loss was determined accurately to within around twenty per cent. Thus this uncertainty caused an error of around $0.2 \%$ in the measured value of enthalpy.

The enthalpy values derived from their measurements were accurate to at least $0.25 \%$. Since measurements at each pressure and temperature were repeated several times the average error will most likely be smaller than the above estimate.

The experimental values of enthalpy measured by Havlicek and Miskovsky are given in Table 7 . These enthalpy values have been converted into $\mathrm{B} / \mathrm{lb}$.*

* It was not certain if the Havlicek and Miskovsky measurements were quoted in units of int. cal/gram or cal/gram. The authors of this report considered them to be calories/gram. The difference between the values of two systems amounts to only some five or six parts in ten thousand, while the uncertainty in their measurements of enthalpy amounts to two or three parts in one thousand. 
Table 7

\section{ENTHALPY MEASUREMENTS OF HAVLICEK AND MISKOVSKY IN THE CRITICAL REGION}

(Enthalpy, B/1b)

\begin{tabular}{|c|c|c|c|c|c|}
\hline $\begin{array}{c}\text { Press., } \\
\text { Pemp. } \\
{ }^{\circ} \text { F }\end{array}$ & 2844.68 & 3200.27 & 3555.85 & 3911.44 & 4267.02 \\
\hline 68 & & & & & \\
212 & 44.161 & - & - & - & 48.190 \\
392 & 186.71 & - & - & - & 189.85 \\
572 & 368.85 & - & - & - & 370.56 \\
662 & 572.38 & - & - & - & 569.69 \\
680 & 706.22 & 700.55 & 697.59 & 693.27 & 690.57 \\
698 & 747.59 & 737.52 & 730.50 & 724.74 & 720.43 \\
716 & 1098.2 & 790.58 & 771.15 & 760.36 & 752.36 \\
734 & 1152.0 & 1073.0 & 845.45 & 805.87 & 792.74 \\
752 & 1189.7 & 1133.6 & 1053.6 & 900.67 & 845.99 \\
770 & 1216.2 & 1173.9 & 1119.9 & 1046.2 & 945.28 \\
842 & - & - & - & - & 1047.3 \\
932 & 1319.4 & 1295.5 & 1274.1 & 1246.8 & 1219.4 \\
1022 & 1394.8 & 1380.6 & 1364.0 & 1348.0 & 1330.77 \\
\hline
\end{tabular}

The error estimate of Havlicek and Miskovsky appears to be realistic in view of their elaborate experimental setup as well as the care exercised by them throughout the course of their investigations. With the exception of the three measured values of Callendar and Egerton their results $(21)$ are the only direct measurements available for the enthalpy of superheated water vapor and subcooled water in the region of interest of this report.

The Callendar and Egerton enthalpy measurements were obtained for pressures between 142.2 and $3200 \mathrm{psia}\left(10\right.$ to $225 \mathrm{~kg} / \mathrm{cm}^{2}$ ) and temperatures from 392 to $1112^{\circ} \mathrm{F}\left(200\right.$ to $\left.600^{\circ} \mathrm{C}\right)$. They stated that about 392 separate measurements of enthalpy were undertaken in the period from 1931 to 1940.

The temperature of the water vapor in the high and low pressure chambers along with the inlet and outlet temperatures of the cooling water were measured with resistance thermometers. Apparently these measurements were more precise than those in the Havlicek and Miskovsky investigations. For example, Egerton and Callendar estimate that all temperatures were measured to at least within $0.04^{\circ} \mathrm{C}$. They further 
stated that in the near vicinity of the saturation line special precautions were taken to measure the temperature of the water vapor in the high pressure chamber to at least $0.02^{\circ} \mathrm{C}$.

The measurement of pressure was achieved with an apparatus consisting of a spring balance and dial. They stated(10) that the pressure was measured and remained constant to within $0.03 \mathrm{~kg} / \mathrm{cm}^{2}$. Apparently the pressure measurement of Callendar and Egerton was also made more precisely than that by Havlicek and Miskovsky.

The main difference between the measurement of Callendar and Egerton and those by Havlicek and Miskovsky was in the duration of a test. In the former experiments an individual test run lasted for about two minutes. In the latter experiments an individual test $r$ un lasted for about three hours. Callendar and Egerton found that it was not possible to maintain steady pressures and temperatures for periods longer than two minutes. They utilized elaborate and refined electronic instruments which metered the flow rate of the condensate and the cooling water. They estimated that the ratio $\mathrm{m}_{\mathrm{w}} / \mathrm{m}_{\mathrm{V}}$ was determined with an accuracy of about two parts in ten thousand. Thus, apparently even this measurement was made with more precision than that by Havlicek and Miskovsky.

Callendar and Egerton initially used the 1930 specific heat values of Osborne et al.(51) for $\mathrm{C}_{\mathrm{p}_{\mathrm{w}}}$ in Equations 19 and 20. However in their final series (which they recommend) the 1939 specific heat values of Osborne et al. (55) were employed for $\mathrm{C}_{\mathrm{p}_{\mathrm{w}}}$. They $(10)$ stated that the 1939 specific heat measurements changed their values of enthalpies by 0.38 to $0.49 \mathrm{cal} / \mathrm{gram}$. It is interesting to point out that Havlicek and Miskovsky suspected that an uncertainty of $0.44 \mathrm{cal} / \mathrm{gram}$ could result in enthalpy through the use of the 1930 Osborne et al. data. However Havlicek and Miskovsky were forced to use the 1930 Osborne et al. data as these were the heat available at the time.

The total heat loss that occurred in the enthalpy experiments of Callendar and Egerton amounted to as much as one per cent of the values of enthalpy. By painstaking calibrations the heat los ses were corrected and could be accounted for to within $\pm 0.3 \mathrm{cal} / \mathrm{gram}$, i.e., to within $0.05 \%$ of the total value of enthalpy.

If these estimates are correct, the experimental results of Callendar and Egerton are somewhat more precise than those of Havlicek and Miskovsky. They $(10)$ estimated that their measurements on the average are accurate to within $0.5 \mathrm{cal} / \mathrm{gram}$. Their measured values of enthalpy in the critical region are given in Table 8 . 
Table 8

\section{ENTHALPY ME ASUREMENTS OF CALLENDAR AND EGERTON IN THE CRITICAL REGION}

(Enthalpy, B/1b)

\begin{tabular}{|c|c|c|}
\hline $\begin{array}{c}\text { Pemp., } \\
{ }^{\circ} \text { Press., } \\
\text { psia }\end{array}$ & 2844.68 & 3200.27 \\
\hline 707 & & \\
752 & 1129.14 & - \\
797 & 1215.18 & 1172.88 \\
842 & 1269.72 & 1243.80 \\
887 & 1316.52 & 1296.00 \\
932 & 1356.84 & 1340.10 \\
977 & 1391.94 & - \\
1022 & 1425.06 & - \\
1067 & 1457.10 & - \\
1112 & 1488.60 & - \\
\hline
\end{tabular}

A comparison between the values of Tables 7 and 8 shows good agreement. The maximum deviations tend to occur at high temperatures. The maximum deviation is around $3.5 \mathrm{~B} / \mathrm{lb}(2 \mathrm{cal} / \mathrm{g})$. It should be pointed out that this is within the combined estimates of error in the measurements of Havlicek and Miskovsky and those of Callendar and Egerton. It is interesting, but perhaps not significant, to note that the data of Havlicek and Miskovsky tend to be somewhat higher than that of Callendar and Egerton.

The data of Tables 7 and 8 show that enthalpy varies markedly with pressure and temperature in the critical region. In view of this variation it is extremely difficult to interpolate measurements to secure reliable values at intermediate values of pressure and temperature. The next chapter describes in detail the methods used in this work to obtain reliable values for the enthalpy at intermediate pressure and temperature conditions.

D. Summary

1. Havlicek and Miskovsky and Callendar and Egerton were the only investigators to measure the enthalpy in the critical region.

2. The accuracy in the measurements of Havlicek and Miskovsky has been estimated at about two or three parts in one thousand. On the 
other hand Callendar and Egerton estimate that their measurements are accurate to well within one part in one thousand.

3. The accord between the two sets of measurements is excellent. A maximum deviation of about two or three parts in one thousand exists. The average deviation is well within a part in one thousand. 


\section{CHAPTER VII \\ ENTHALPY VALUES DERIVED IN THIS WORK}

A. General

This chapter describes the method used in this work to derive enthalpy values from the available specific heat measurements. These various measurements were considered as a single body of data. The accord achieved upon doing this is noteworthy. The values of enthalpy derived are for pressures of $200,225,230,240,250,260,275,290$ and $300 \mathrm{~kg} / \mathrm{cm}^{2}$ and temperatures from 360 to $400^{\circ} \mathrm{C}$.

B. Experimental Data Utilized

\section{Specific Heat Measurements}

It was stated in the Introduction that the present authors analyzed the various specific heat at constant pressure measurements on water substance in the critical region. (49) The study indicated that reliable measurements were made by Havlicek and Miskovsky, (21) Koch(35) Russkazov and Sheindlin, (58) Sheindlin, (61) Sirota and Maltzev (62) and Timrot.(67) The data which proved convenient to use in this work was that by Havlicek and Miskovsky, Koch, Sirota and Maltzev and Timrot.

Koch's measurements extended to 2844 psia $\left(200 \mathrm{~kg} / \mathrm{cm}^{2}\right)$. Havlicek and Miskovsky and Timrot conducted measurements along several isobars between 2844 and $4267 \mathrm{psia}\left(200\right.$ to $\left.300 \mathrm{~kg} / \mathrm{cm}^{2}\right)$. Sirota and Maltzev conducted measurements along isobars between 4267 and 7110 psia $\left(300\right.$ to $\left.500 \mathrm{~kg} / \mathrm{cm}^{2}\right)$.

\section{Other Experimental Data}

Koch in 1932 made enthalpy difference measurements along the $240 \mathrm{~kg} / \mathrm{cm}^{2}$ isobar on that portion where the specific heat, $\mathrm{C}_{\mathrm{p}}$, attains a maximum. The enthalpy changes in this region by $100 \mathrm{cal} / \mathrm{g}$ in about six degrees. It proved convenient to compare the variation of enthalpy with temperature as measured by Koch with the variation deduced in this work along the $240 \mathrm{~kg} / \mathrm{cm}^{2}$ isobar.

It was stated previously in Chapter III that Koch, (37) in 1934, conducted enthalpy of vaporization experiments along various isobars up to $2344 \mathrm{psia}\left(200 \mathrm{~kg} / \mathrm{cm}^{2}\right)$. The results of Koch given in Table I were also utilized to derive enthalpy values.

The next section outlines the method used in this work to derive values of enthalpy from the above specific heat and enthalpy of vaporization experiments. 
C. Theoretical Basis for the Method Used to Derive Enthalpy Values

By definition the mean specific heat over a temperature interval, $\Delta \mathrm{T}$, is defined as

$$
\mathrm{C}_{\mathrm{p}_{\text {mean }}} \equiv\left\{\frac{\Delta h}{\Delta \mathrm{T}}\right\}_{\mathrm{p}}
$$

In the various specific heat measurements heat was transferred to or from a predetermined flow of water vapor and the corresponding change in tem perature was noted. The specific heat was computed by the various inves tigators by means of the following relation.

$$
C_{p_{\text {mean }}}=\left\{\frac{Q}{G \Delta T}\right\}_{p}
$$

where

$Q$ is the rate at which heat is transferred to or from the calorimeter

$G$ is the rate of flow of water vapor through the calorimeter

$\Delta T$ temperature difference of the fluid at the entrance and exit of the calorimeter.

Thus the enthalpy difference corresponding to a temperature difference $\Delta T$ is identically equal to $Q / G$. Koch, Havlicek and Miskovsky, Timrot and Sirota and Maltzev presented their results in such a manner that it was possible to compute values of $\Delta \mathrm{h}$ for each of their individual measurements of specific heat.

The next basic step was to choose base values of enthalpies along the $200,225,230,240,250,260,275,290$ and $300 \mathrm{~kg} / \mathrm{cm}^{2}$ isobars. The base temperature was arbitrarily chosen as $400^{\circ} \mathrm{C}$. Thus the enthalpy values at this temperature at along the various isobars were based on the enthalpy measurements of Havlicek and Miskorsky, and Callendar and Egerton.

Along the 200,225 and $230 \mathrm{~kg} / \mathrm{cm}^{2}$ isobars it was found necessary to utilize a second base temperature and value of enthalpy. This condition was arbitrarily selected at $370^{\circ} \mathrm{C}$. There are two basic reasons for the necessity of a second base value along isobars in the near vicinity of the critical point. The first reason is that in the subcritical region it is necessary to have a base value of enthalpy for subcooled water and for superheated vapor along a given subcritical isobar, $\mathrm{p}<\mathrm{p}_{\mathrm{c}}$. The second reason is that the isobars. $\mathrm{p}>\mathrm{p}_{\mathrm{c}}$, not far removed from critical pressure undergo a marked and 
rapid change of enthalpy with a small change in temperature. This variation makes it very difficult to maintain precision in any analysis. Less error is introduced consequently if base values of enthalpy are chosen on either side of inflection temperature in regions where the variation of enthalpy with temperature is less marked.

The various experimental data were arranged in such a manner that the temperature interval between measurements was a minimum. The reason for this was to reduce the error in the derived values of enthalpy.

An increment $\Delta \mathrm{h}^{\prime}$ was initially computed for the temperature increment, $\Delta \mathrm{T}^{\prime}$, between a base temperature and either the inlet or outlet temperature of a given specific heat measurement. The increment $\Delta h^{\prime}$ was computed by means of the following relation

$$
\Delta \mathrm{h}^{\prime}=\mathrm{C}_{\mathrm{p}}^{\prime}\left(\mathrm{T}_{\mathrm{B}}-\mathrm{T}_{1,2}\right)
$$

where $\mathrm{C}_{\mathrm{p}}{ }^{\prime}$ is the mean specific heat over the temperature increment,
$\Delta T^{\prime}=T_{B}-T_{1}, 2$

$T_{B}$ is the base temperature

$T_{1,2}$ is either the inlet or outlet of a given specific heat measurement.

Thus the enthalpy at the temperature $T_{1,2}$ is related to the enthalpy $h_{B}$ at $\mathrm{T}_{\mathrm{B}}$ by the following relation

$$
h_{1,2}=h_{B}-\Delta h^{\prime}
$$

where $h_{1}, 2$ is the enthalpy at the temperature $T_{1}, 2$. The experimental enthalpy difference, $Q / G$ was then added algebraically to $h_{1}, 2$ to obtain the enthalpy at either the outlet or inlet temperature corresponding to $\mathrm{T}_{1}, 2$. By means of a reiterative process enthalpy values were derived along all isobars where specific heat measurements were made.

The values of $\mathrm{C}_{\mathrm{p}}$ ' were obtained from a diagram constructed according to the measurements of Havlicek and Miskovsky, Koch, Timrot and Sirota and Malzev. Such diagrams may be found in reference 49.

Much attention was paid to ensure that the computed values $\Delta \mathrm{h}^{\mathrm{p}}$ amounted to only several per cent in comparison to the experimental determination of $\Delta h=Q / G$. There were only two cases where $\Delta h^{\prime}$ 
exceeded $Q / G$. These both occurred on the $230 \mathrm{~kg} / \mathrm{cm}^{2}$ isobar at temperatures of $386^{\circ} \mathrm{C}$ and $375.75^{\circ} \mathrm{C}$. It should be emphasized though that in the large majority of the calculations $\Delta \mathrm{h}^{\prime}$ was appreciably less than ten per cent of $Q / G$. This condition was only achieved after several unsuccessful arrangements and computations were attempted.

D. Derived Enthalpy Values

Figure 6 gives values of enthalpy derived by the methods outlined in the previous section. In view of the relatively small amount of deviation between the various enthalpy values it may be concluded that the individual measurements of $Q / G$ and $\Delta T$ in the investigations of Havlicek and Miskovsky, Koch, Timrot and Sirota and Maltzev are equally accurate. This agreement justifies our previous assumption in considering the above measurements as a single unified body of data.

The accord between the measured enthalpy values of Havlicek and Miskovsky and the values derived in this work is noteworthy. For example, in Figure 6 there are some four hundred and seventy values of enthalpy and all but eighty-five deviate from a best line by less than $0.5 \mathrm{cal} / \mathrm{g}(1 \mathrm{~B} / \mathrm{lb})$. Furthermore there are respectively thirty-five and nine values which deviate from a best line by more than 1 and $2 \mathrm{cal} /$ gram. Thus it may be concluded that in the large majority of the cases the deviations of individual values from a best line are entirely within one or two parts in one thousand, i.e., entirely within experimental uncertainty.

It is necessary to know enthalpy at intermediate values of pressure and temperature. Consequently the results of Figure 6 were utilized. to obtain lines of constant enthalpy on a pressure-temperature diagram. Such a diagram is given in Figure 7. The isenthalpic curves possess very slight curvature. By graphical differentiation, values may be obtained for the Joule-Thompson coefficient, i.e., $\mu=(\partial \mathrm{T} / \partial \mathrm{P})_{\mathrm{h}}{ }^{\text {. When }}$ direct measurements of the Joule-Thompson coefficients become available a comparison will be possible between the values obtained from this work and directly measured values.

Figure 7 indicates good consistency between the pressuretemperature values. However attention is directed to the deviations along the 275 and $290 \mathrm{~kg} / \mathrm{cm}^{2}$ isobar in the region where the enthalpy is less than $900 \mathrm{~B} / \mathrm{lb}(500 \mathrm{cal} / \mathrm{g})$. Evidently the directly measured values of enthalpy along with the values of this work derived from the Timrot specific heat measurements are in error below a temperature of $734^{\circ} \mathrm{F}$ $\left(390^{\circ} \mathrm{C}\right)$. It is recommended that these isobars be reinvestigated for both specific heat and enthalpy for temperatures below $390^{\circ} \mathrm{C}$. However, the error in enthalpy is very small. For example by means of Figures 6 and 7 it may be concluded that Havlicek and Miskovsky's measured value of enthalpy at $275 \mathrm{~kg} / \mathrm{cm}^{2}$ and $380^{\circ} \mathrm{C}$ is $10 \mathrm{w}$ by about $1 \mathrm{cal} / \mathrm{gram}(2 \mathrm{~B} / 1 \mathrm{~b})$. 


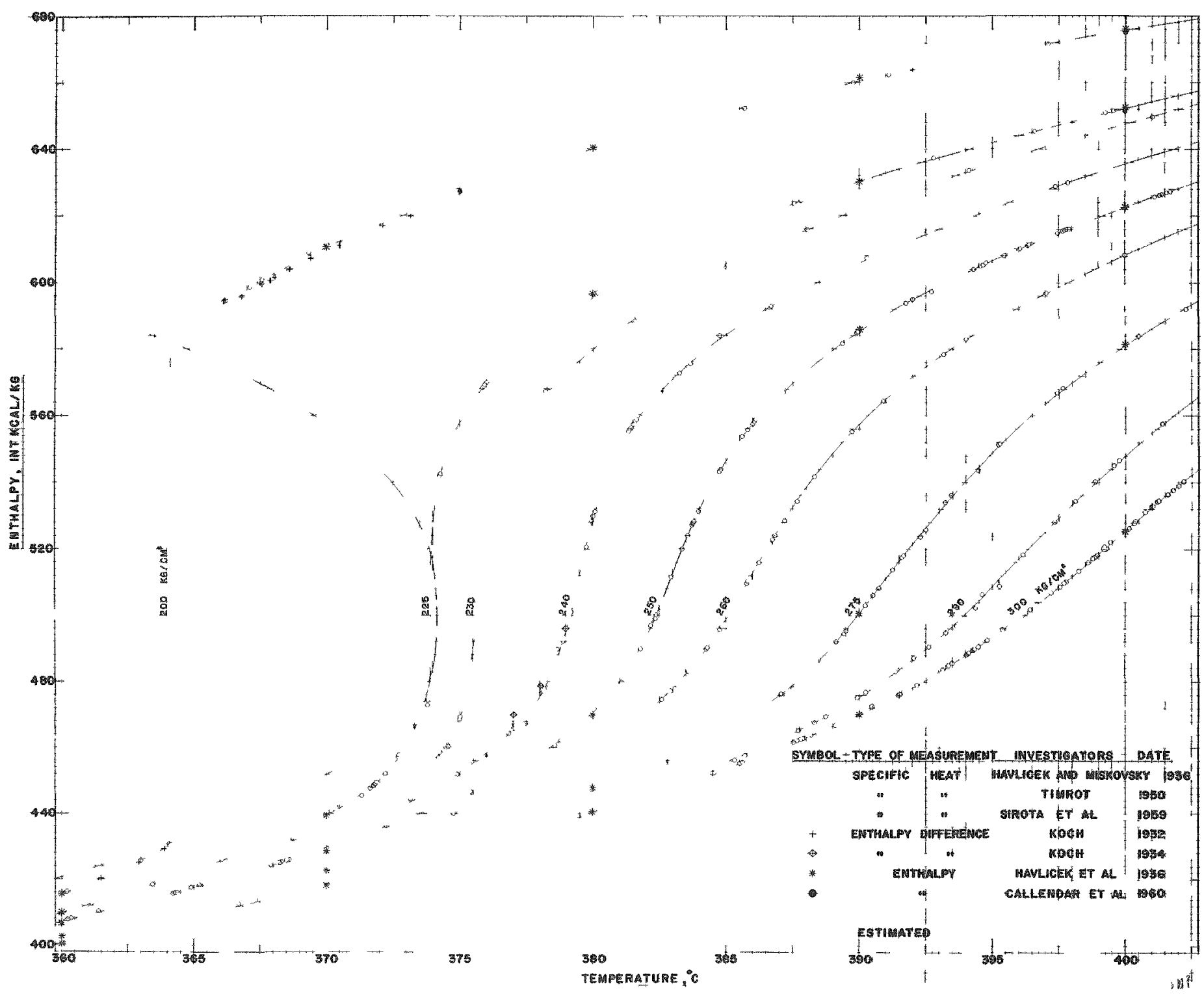

Fig. 6. Values of Enthalpy Derived from Experimental Data 


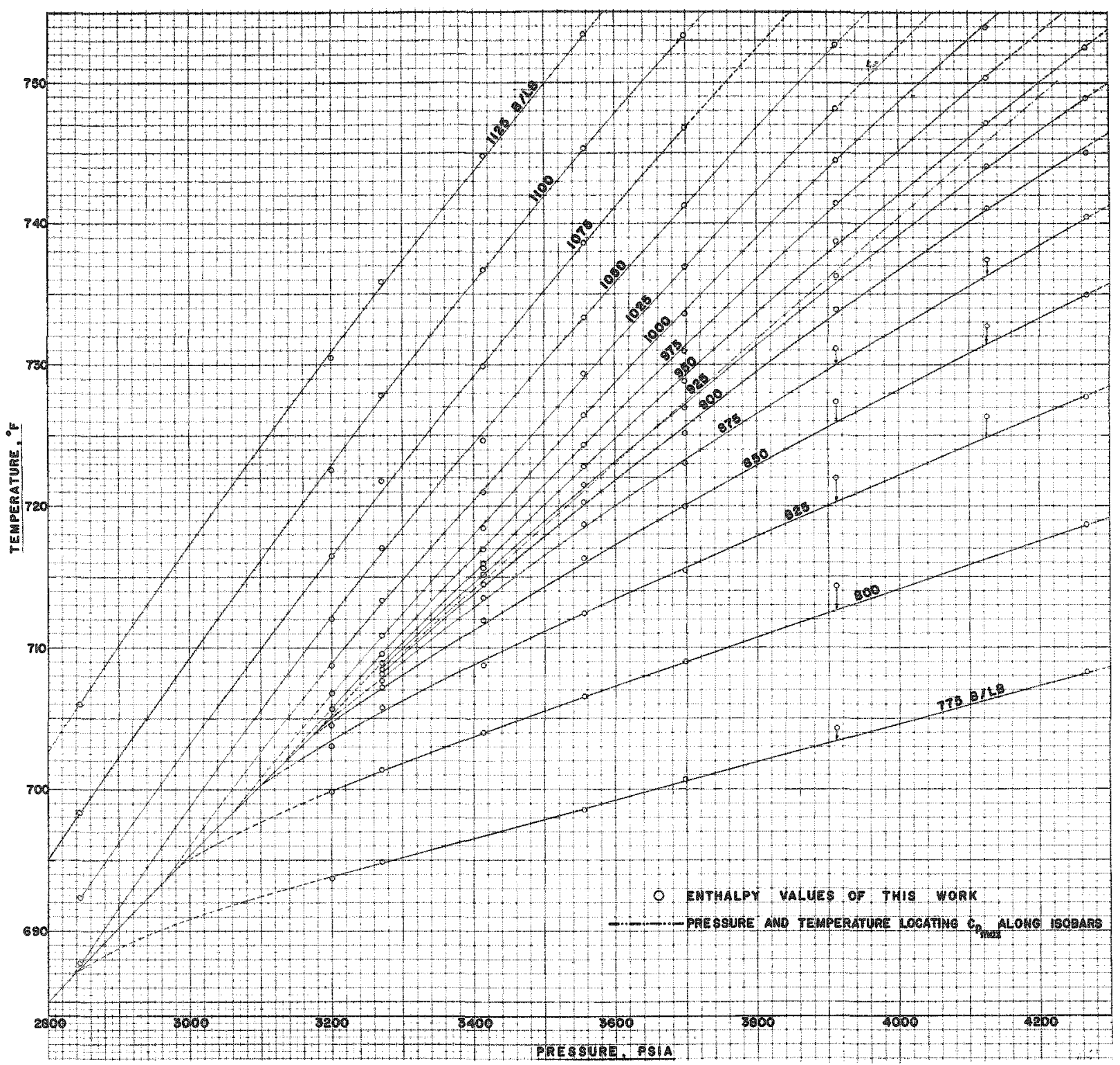

Fig. 7. Isenthalpic Curves for Water in the Critical Region 
The values of enthalpy obtained from isenthalpic curves of Figure 7 are recommended for use. Time did not permit a comparison to be made between values so obtained with those of other steam tables.

E. Summary

1. The values of enthalpy of this work derived from the specific heat measurements of Koch, Havlicek and Miskovsky, Timrot and Sirota and Maltzev are in surprisingly good accord with the directly measured values of Havlicek and Miskovsky.

2. The values so obtained are estimated to be accurate to some one or two parts in one thous and.

3. The directly measured values of enthalpy for temperatures below $390^{\circ} \mathrm{C}$ along the $275 \mathrm{~kg} / \mathrm{cm}^{2}$ isobar possess a small error. For example it is possible that the measured value of enthalpy at $380^{\circ} \mathrm{C}$ is low by the amount of $1 \mathrm{cal} / \mathrm{g}$.

4. Isenthalpic lines in the critical region possess very small curvature. Values for the Joule-Thompson coefficient from this work should be compared with directly measured values when these become available. 
CHAPTER VIII

\section{INTERPOLATION TECHNIQUES AND SOME BOUNDARY CONDITIONS FOR A RELIABLE ENTHALPY FORMULATION}

A. General

This present chapter gives information about a useful interpolation technique which may be used to derive reliable values of enthalpy in the critical region.

A very sensitive test to evaluate the accuracy and consistency of P-V-T measurements and enthalpy measurements is described. Furthermore some boundary conditions which have escaped previous attention are considered.

\section{B. A Useful Interpolation Technique}

In the critical region it is extremely difficult to maintain precision in analysis as may be seen from an inspection of Figure 5 . The chief reason for this difficulty is due to the marked variation of enthalpy with temperature and pressure (Figure 6). Thus the need for a reliable interpolation technique is apparent.

It may be seen from Figure 6 that $(\partial \mathrm{h} / \partial \mathrm{T})_{\mathrm{p}}$ is large in the critical region. Theoretically, the value of $(\partial \mathrm{h} / \partial \mathrm{T})_{\mathrm{p}}$ at the critical point is infinite. It would be very difficult to obtain a formulation which would both represent data to within experimental accuracy and which would yield an infinite value for $(\partial h / \partial T)_{p}$ at the critical point.

The interpolation technique developed in this section is based on a system of coordinates for which the variation of enthalpy along the critical isobar is not infinite at the critical point. It is a graphical technique but it should be emphasized that a semi-theoretical formulation might be developed by utilizing certain of its principles. However, time did not permit the authors to develop such a formulation and therefore only certain preliminary ideas will be presented here.

After a preliminary checking of possible coordinate systems it was decided to use the product of enthalpy - temperature, $h t$ as the ordinate and the enthalpy, $h$, as the abscissa with pressure as a parameter. The main reason for using this system of coordinates is that such isobaric curves have a finite slope at the critical point. The reason for this is that the derivative,

$$
\left\{\frac{\partial(h t)}{\partial h}\right\}_{p}=t+\frac{h}{C_{p}},
$$


is finite since at the critical point $C_{p}$ is infinite and therefore

$$
\left\{\frac{\partial(h t)}{\partial h}\right\}_{p_{C^{\prime}}, t_{c}} \equiv t_{c}
$$

The measurements of Havlicek and Miskovsky and of Callendar and Egerton and, the values of this work which were derived from specific heat measurements, were plotted on a diagram of $\mathrm{ht}-\mathrm{h}$ with pressure as a parameter. A small scale reproduction of such a diagram with only a few selected isobars is shown in Figure 8 . It may be seen that the isobars are gently sloping curves with finite values for the derivatives.

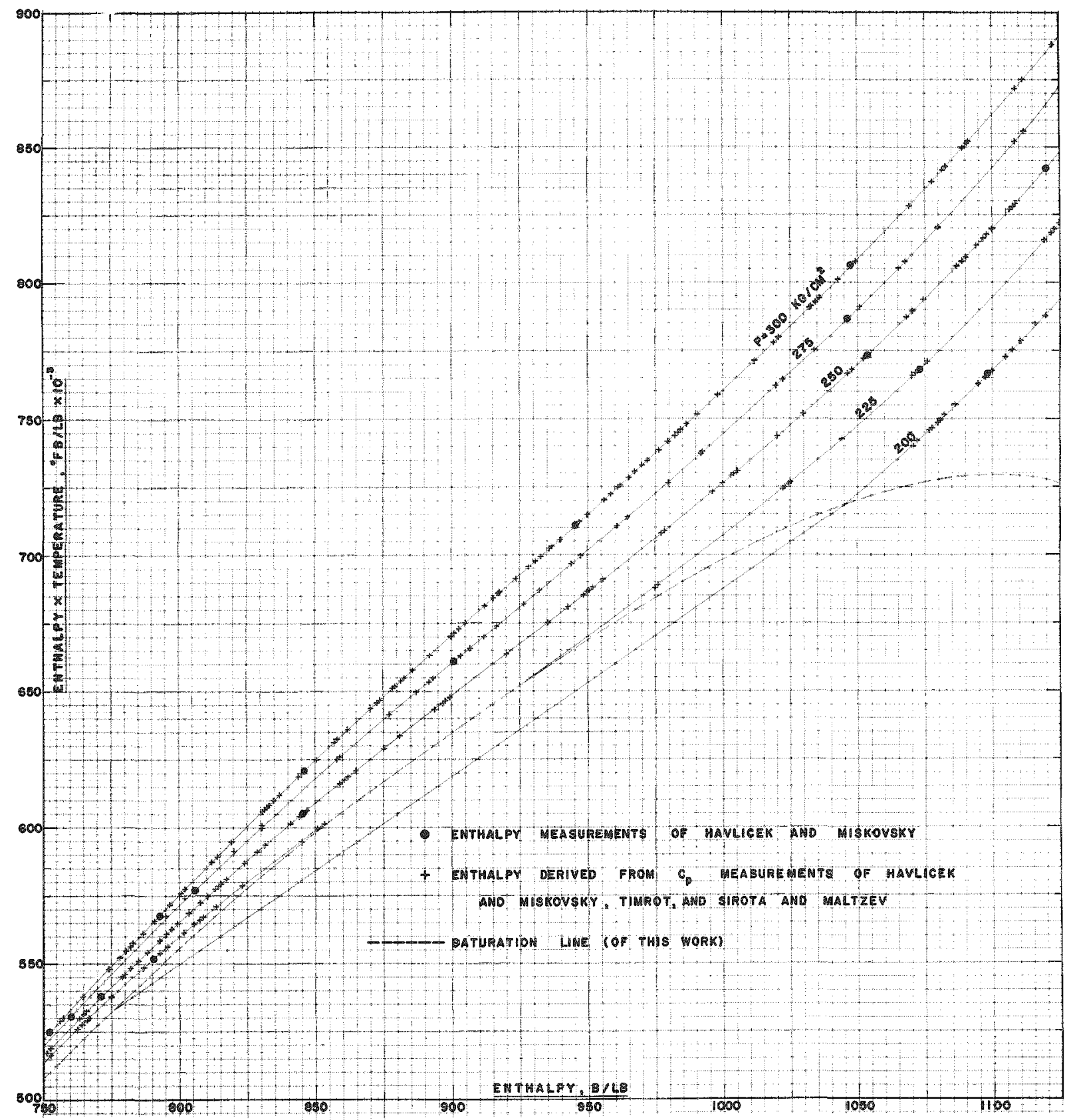

Fig. 8

The Variation of the Enthalpy-temperature Product with Enthalpy along Isobars 
It is interesting to mention that the inflection of the isobars of Figure 8 appears to occur at enthalpy values between 900 and $920 \mathrm{~B} / 1 \mathrm{~b}$. In Chapter IV the enthalpy at the critical point was estimated at about $900 \mathrm{~B} / 1 \mathrm{~b}$. The uncertainty in this latter value might be as high as two or three per cent. Thus it is reasonable to conclude that within experimental error the isobars of Figure 8 undergo inflection in the immediate vicinity of the critical enthalpy value, $h_{C}=900 \mathrm{~B} / 1 \mathrm{~b}$.

\section{Consistency between Volumetric and Calorimetric Data}

If volumetric and enthalpy data are available it is possible to check their internal consistency by means of thermodynamic relations. Even though this is desirable much checking of the consistency of various data for water vapor in the critical region remains to be done. In this section an analysis is made of a certain boundary condition which has previously escaped attention.

Havlicek and Miskovsky made some interesting deductions by starting with the following well-known thermodynamic relation,

$$
\frac{1}{T^{2}}\left(\frac{\partial h}{\partial p}\right)_{T}=-\frac{1}{J P}\left\{\frac{\partial(P V / T)}{\partial T}\right\}_{p} \text {, }
$$

They constructed various isobars of $1 / \mathrm{T}^{2}(\partial \mathrm{h} / \partial \mathrm{P}) \mathrm{T}$ versus temperature $\mathrm{T}$ on the basis of their enthalpy measurements. (21) Figure 9 shows several isobars of $-1 / \mathrm{T}^{2}(\partial \mathrm{h} / \partial \mathrm{P})_{\mathrm{T}}$ versus $\mathrm{T}$ as determined by Havlicek and Miskovsky.

Havlicek and Miskovsky gave no details of the graphical techniques they employed to construct the isobars of Figure 9. They stated however that the maxima of $-1 / \mathrm{T}^{2}(\partial \mathrm{h} / \partial \mathrm{P})_{\mathrm{T}}$ occurred along the 350 and $400 \mathrm{~kg} / \mathrm{cm}^{2}$ at temperatures of 425 and $435^{\circ} \mathrm{C}$. They also noted that the maxima of $-1 / \mathrm{T}^{2}(\partial \mathrm{h} / \partial \mathrm{P})_{\mathrm{T}}$ along various isobars in the supercritical region separate the regions in which steam possesses a 'water' property and a 'gas' property.

Both Euken (17) and Jakob(26) reported on the existence of two phases of water vapor above the critical point. The authors of this present work also concerned themselves with the region separating the phases of supercritical liquid and supercritical vapor. It was shown, for example in reference 49 , that the locus on a pressuretemperature diagram defining the conditions $\left(\partial \mathrm{C}_{\mathrm{p}} / \partial \mathrm{p}\right)_{\mathrm{T}}=(\partial \beta / \partial \mathrm{p})_{\mathrm{T}}=0$, coincides exactly with the critical isochoric line. It was also shown in reference 49 that the locus on a pressure-temperature diagram defining the conditions $(\partial \beta / \partial \mathrm{T})_{\mathrm{p}}=\left(\partial \mathrm{C}_{\mathrm{p}} / \partial \mathrm{T}\right)_{\mathrm{p}}=0$ was a curve gradually diverging from the critical isochoric line in the direction of high densities. 


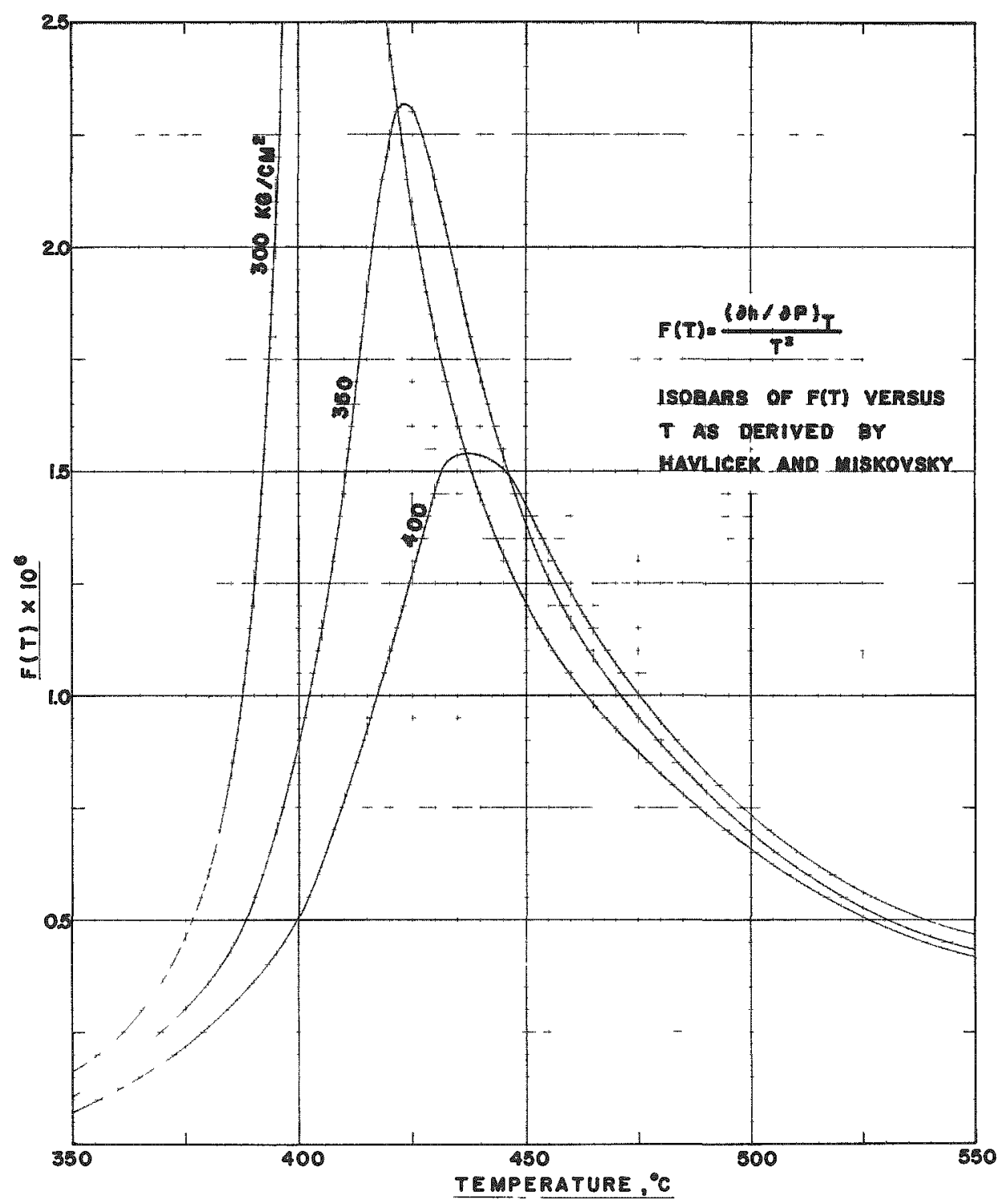

Fig. 9. Variation of $F(T)$ with Temperature along Three Isobars

It was concluded, therefore, that the region encompassed by the above mentioned 'curves' may separate so-called supercritical fluid region from the so-called supercritical vapor region.

In view of the preceding analysis a more definite statement may be made about the location of the maxima of $-1 / \mathrm{T}^{2}(\partial \mathrm{h} / \partial \mathrm{p})_{\mathrm{T}}$ along isobars. At a maximum or an isobaric curve of $-1 / \mathrm{T}^{2}(\partial \mathrm{h} / \partial \mathrm{p}) \mathrm{T}$ versus $\mathrm{T}$ the following condition must be valid

$$
-\left[\frac{\partial}{\partial T}\left\{\frac{1}{T^{2}} \frac{\partial h}{\partial p}\right\}_{T}\right]_{p}=-\frac{1}{T^{2}}\left(\frac{\partial C_{p}}{\partial p}\right)_{T}+\frac{2}{T^{3}}\left(\frac{\partial h}{\partial p}\right)_{T}=0
$$


and

$$
\left(\frac{\partial C_{p}}{\partial p}\right)_{T}=\frac{2}{T}\left(\frac{\partial h}{\partial p}\right)_{T}
$$

In the region of interest of this work the change of enthalpy with pressure along any given isotherm is negative. Thus the change of specific heat with pressure along the same isotherm is necessarily negative. Thus in view of the fact that $\left(\partial \mathrm{C}_{\mathrm{p}} / \partial \mathrm{p}\right)_{\mathrm{T}}=-\mathrm{T}\left(\partial^{2} \mathrm{~V} / \partial \mathrm{T}^{2}\right)_{\mathrm{p}}$ it may be concluded that the second partial derivative of specific volume with respect to temperature at constant pressure must be necessarily positive. Thus the temperature corresponding to the maxima of the isobaric curves of Figure 9 must be somewhat lower than the temperature at which the corresponding isobaric curve of specific volume and temperature is undergoing inflection.

It would be of importance to attempt to verify the above conclusions. To do this the following assumptions must be made:

1. The locus of points defining the maxima of specific heat along various isotherms or the condition of inflection on isobaric curves of specific volume and temperature is coincident with the pressure and temperature of the critical isochoric line to a pressure of $400 \mathrm{~kg} / \mathrm{cm}^{2}$.

2. The pressure and temperature relation derived for the critical isochoric line in reference 44 is valid to $400 \mathrm{~kg} / \mathrm{cm}^{2}$.

It should be mentioned that these assumptions hold definitely for pressures to at least around $300 \mathrm{~kg} / \mathrm{cm}^{2}$.

The temperatures corresponding to pressures of 350 and $400 \mathrm{~kg} / \mathrm{cm}^{2}$ at the critical specific volume were computed as 420 and $438^{\circ} \mathrm{C}$. Along these same isobars the maximum of $-1 / T^{2}(\partial \mathrm{h} / \partial \mathrm{p})_{T}$ occurred at temperatures of 425 and $435^{\circ} \mathrm{C}$ respectively. Thus the theoretical condition interestingly enough has been verified for the $400 \mathrm{~kg} / \mathrm{cm}^{2}$ isobar. However the condition (that the temperature locating the maxima of $-1 / T^{2}(\partial \mathrm{h} / \partial \mathrm{p})_{\mathrm{T}}$ be somewhat lower than the temperature at which isobaric curves of specific volume versus temperature are undergoing inflection) is not verified for the $350 \mathrm{~kg} / \mathrm{cm}^{2}$ isobar.

There are several plausible reasons as to why the theoretical conditions are not completely verified. One reason is that the maximum of $-1 / \mathrm{T}^{2}(\partial \mathrm{h} / \partial \mathrm{p})_{\mathrm{T}}$ along the $350 \mathrm{~kg} / \mathrm{cm}^{2}$ isobar as determined by Havlicek and Miskovsky is in error. This is a reasonable conjecture since there are no direct measurements of enthalpy in the interval between 400 and $450^{\circ} \mathrm{C}$ along the $350 \mathrm{~kg} / \mathrm{cm}^{2}$ isobar. Thus, in order to clarify the situation, more enthalpy measurements should be made along the $350 \mathrm{~kg} / \mathrm{cm}^{2}$ isobar. It might also be desirable to conduct enthalpy measurements along several 
isobars between 300 and $400 \mathrm{~kg} / \mathrm{cm}^{2}$. If this is not possible use should be made of volumetric data that is already in existence to compute values of the analogous or completely equivalent quantity, $(1 / \mathrm{P})\{\partial(\mathrm{PV} / \mathrm{T}) / \partial \mathrm{T}\} \mathrm{p}^{\prime}$ along various isobars between 300 and $400 \mathrm{~kg} / \mathrm{cm}^{2}$. If both enthalpy and volumetric data are available a rigourous check on their accuracy would be a comparison of the isobars $-1 / \mathrm{T}^{2}(\partial \mathrm{h} / \partial \mathrm{p}) \mathrm{T}$ versus $\mathrm{T}$ with isobars of $(1 / P)\{\partial(P V / T) / \partial T\}_{p}$.

Anothe $r$ equally plausible reason for theory being not in agreement with observation is that the relation $P=2.72(t-374.15)+225.6$ assumed for the pressure and temperature along the critical specific volume is no longer valid for pressures above $300 \mathrm{~kg} / \mathrm{cm}^{2}$. However it is strange, even though it might be coincidental, that theory is in agreement with measurement along the $400 \mathrm{~kg} / \mathrm{cm}^{2}$ isobar.

The foregoing discussion indicates that considerable analysis must be undertaken to clarify certain points and to verify theory. Furthermore such analysis will ultimately yield a development of a fundamental and rational equation of state which may be valid for many other substances.

D. Summary

1. A suitable coordinate system for interpolation purposes was found to be a diagram with the enthalpy temperature product as ordinate and enthalpy as the abscissa with pressure as a parameter. The critical isobar has a slope at the critical point of $\{\partial(h t) / \partial h\}_{P_{C}}, T c=t_{c}$.

2. The points of inflection along isobars of $h t$ versus $h$ were always found to occur at enthalpy values ranging from 900 to $920 \mathrm{~B} / 1 \mathrm{~b}$. This is very close to the value of the enthalpy at the critical point, $h_{c}=900 \mathrm{~B} / \mathrm{lb}$.

3. It may be shown that the temperature corresponding to the maximum value of $-1 / \mathrm{T}^{2}(\partial \mathrm{h} / \partial \mathrm{P})_{\mathrm{T}}$ on isobars is somewhat lower than the temperature at which isobars of volume versus temperature are undergoing inflection. This was verified with various experimental data at a pressure of $400 \mathrm{~kg} / \mathrm{cm}^{2}$. However it was not verified at a pressure of $350 \mathrm{~kg} / \mathrm{cm}^{2}$.

4. Measurements and investigations on enthalpy should continue in order that more definite statements may be made about the above boundary conditions. 


\section{ACKNOW LEDGEMENTS}

The authors appreciate the assistance given to them by the following undergraduate students, D. Cash, N. Dong, A. Floran, H. Habibagahi, R. Hunter, M. Kern, W. Kunimoto, T. Myazaki, J.Repon, and W. Stamper. We are grateful to Professors P. E. Liley and P. McFadden for reading this material upon its completion.

We are appreciative of the interest shown by Professor E.R.G. Eckert of the University of Minnesota and Dr. P. A. Lottes of the Argonne National Laboratory throughout the course of this and other phases of the thermodynamic property and heat transfer investigations on water and water vapor.

This work was carried out through the financial assistance of the Argonne National Laboratory Sub-Contract 31-109-38-704 and the Atomic Energy Commission Contract AT(11-1) - 1026. 


\section{BIBLIOGRAPHY}

1. Anonymous, "International Steam Table Conference - Skeleton Steam Tables," Mechanical Engineering, Vol. 52, pp. 120-122, 1930.

2. Anonymous, "Skeletal Tables for Water and Water Vapor Adopted at the Third International Conference on Steam Tables," Mechanical Engineering, Vol. 57, pp. 710-713, 1935.

3. Anonymous, Revised Steam Tables and Diagrams of the J.S.M.E., The Japan Society of Mechanical Engineers, Second Edition, 1955.

4. Byrne, R. and G. Thodos, "The Enthalpy of Water in the Liquid State," American Institute of Chemical Engineers Journal, Vol. 5, pp. $551-555,1959$.

5. Cagniard de la Tour, Ann. Chim. Phys. Vol. 21, pp. 127, 178, 1822, ibid. Vol. 22, p. 140, 1823, ibid. Vol. 23, p. 410, 1824.

6. Callendar, H. L., "Steam Tables and Equation Extended by Direct Experiment to $4000 \mathrm{lb} / \mathrm{in}^{2}$. and $400^{\circ} \mathrm{C} . "$ Proceedings of the Royal Society, Series A, Vol. 120, pp. 460-472, 1928.

7. Callendar, H. L., "Extended Steam Tables," Proceedings of the Institute of Mechanical Engineers, Vol. 1, pp. 507-527, 1929.

8. Callendar, G.S., and A.C.Egerton, The 1939 Callendar Steam Tables, Edward Arnold and Co., London.

9. Callendar, G.S., "Tables and Diagrams Showing the Extent of Steam Research," Technical Report, Ref. J/T133, British Electrical and Allied Industries Research Association, 1941.

10. Callendar, G. S., and A. Egerton, "An Experimental Study of the Enthalpy of Steam," Philosophical Transactions of the Royal Society of London, Series A, Vol. 252, pp. 133-164, 1960.

11. Davis, H. N., and J.H. Keenan, "Recent Researches on the Thermal Properties of Steam, " World Engineering Congress, Tokyo, Japan, Vol.4, pp. 239-263, 1929.

12. Dorsey, N. E., Properties of Ordinary Water Substance in all its Phases: Water Vapor, Water and all the Ices, Reinhold Publishing Corporation, New York, N. Y., 1940.

13. Dzung, L. S. and W. Rohrbach, Enthalpie - Entropie - Diagramme for Wasserdampf and Wasser, Berlin, Gottingen and Heidelberg, 1955.

14. Eck, H., "Zustandgrössen des Wassers im Kritischen Gebeit" Physikalische Zeitschrift, Vol. 38, p. 256, 1937. 
15. Eck, H., "Investigations on the State of Saturation of Water between $350^{\circ} \mathrm{C}$ and the Critical Temperature," Physikalische Zeitschrift, Vol. 40, pp. 3-15, 1939. (Translated into English, School of Mechanical Engineering, Purdue University, 1960).

16. Egerton, A. C. and G. S. Callendar, "On the Saturation Pressures of Steam (170 to $374^{\circ} \mathrm{C}$ ), "Philosophical Transactions of the Royal Society of London, Series A, Mathematical and Physical Sciences, Vol. 231, pp. 147-205, 1932-33.

17. Euken, A., "Uber die Fortsetzung der Damp'fdruck kurve oberhalb des Kritischen Punktes," Physikalische Zeitschrift, Vol. 35, pp. $708-711,1934$.

18. Faxen, O. H., Thermodynamic Tables in the Metric System for Water and Steam, Nordisk Rotogravyr, Stockholm, Sweden, 1953.

19. Fiock, E. F., "A Review of Calorimetric Measurements on Thermal Properties of Saturated Water and Steam," Journal of Research of the National Bureau of Standards, Vol. 5, pp. 481-505, 1930.

20. Fritsch, C. A. and R. J.Grosh, "A Description of Thermal Conductivity and Dynamic Viscosity of Water in the Critical Region," Argonne National Laboratory Report, ANL-6238, October 1960.

21. Havlicek, J. and L. Miskovsky, "Experiments of the Marsaryk Academy of Work in Prague on the Physical Properties of Water and Steam," Helvetica Physica Acta, Vol. 9, pp. 161-207, 1936. (Translated into English, School of Mechanical Engineering, Purdue University, 1959).

22. Hirschfelder, J. O., "Some Notes on the Virial Theorem and its Application," Theoretical Chemistry Laboratory, University of Wisconsin, CF-2922, March 1961.

23. Jakob, M., "Steam Research in Europe and in America," Lecture \#1, Engineering (London), pp. 518-521, 1931.

24. Jakob, M. and W. Fritz, "The Heat of Vaporization of Water and the Specific Volume of Saturated Steam up to $202 \mathrm{~kg} / \mathrm{cm}^{2},\left(365^{\circ}\right), "$ " Physikalische Zeitschrift, Vol. 36, pp. 651-658, 1935.

25. Jakob, M., "Heat Transfer in Evaporation and Condensation - Part I), Mechanical Engineering, Vol.58, pp.643-660, 1936.

26. Jakob, M., "Concerning the Saturation Curve for Water Vapor above the Critical Point," Physikalische Zeitschrift, Vol. 36, pp. 413-414, 1935. (Translated into English, School of Mechanical Engineering, Purdue University, 1960).

27. Juza, J., "A General Steam Equation in the Range $0-800^{\circ} \mathrm{C}$ and 0 - 2500 Bars," Acadeny of Sciences of Czechoslovakian Research Institute of Machinery, Prague, June 12, 1958. (Available from Professor Juza at the above address). 
28. Juza, J. "A General Steam Equation in the Range $0-800^{\circ} \mathrm{C}$ and 0 - 2500 Bars, Part II," Academy of Sciences of Czechoslovakia, Research Institute of Machinery, Prague, July 8, 1958. (Available from Professor Juza at the above address.)

29. Juza, J., "An Equation of State for Saturated and Superheated Water Vapor," Teploenergetika, Vol. 7, No. 10, pp.80-90, 1960.

30. Kazavchinsky, J. Z. and O. I. Kathe, "Equation of State of Water Vapor," Teploenergetika, Vol.5, No. 7, pp. 26-30, 1958.

31. Keenan, J. H. and F.G.Keyes, Thermodynamic Properties of Steam, First Edition, John Wiley and Sons, New York, N。Y。 1953.

32. Keyes, F.G., L. B. Smith, and H. T. Gerry, "The Specific Volume of Steam in the Saturated and Superheated Conditions Together with the Derived Values of Enthalpy, Entropy, Heat Capacity and JouleThompson Coefficients," Proceedings of the American Academy of Arts and Science, Vol. 70, pp. 319-364, 1936.

See also,

Keyes, F. G., "The Consistency of Thermodynamic Data for Water Substance Vapor Phase to $550^{\circ} \mathrm{C}$, Part VII, "The Journal of Chemical Physics, Vol. 17, pp. 923-935, 1949.

33. Keyes, F. G., "The 1957 Status of the Steam Properties, "Trans actions of the ASME, Vol. 80, pp.555-560, 1958。

34. Koch, W., "The Behaviour of Water in the Critical Region," Forschung auf dem GebieteIngenierwesens, Vol.3, pp.189-192. 1932. (Translated into English, School of Mechanical Engineering. Purdue University, 1960).

35. Koch, W., "The Specific Heat of Superheated Steam for Pressure from 120 to 200 ata and of the Saturation Temperature to $450^{\circ} \mathrm{C}$ " " Forschung auf dem Gebiete Igenieurwesens, Vol。3, pp.1-10, 1932. (Translated into English, School of Mechanical Engineering. Purdue University, 1960).

36. Koch, W., "The Specific Heat of Water from 0 to $350^{\circ} \mathrm{C}$ and from Saturation Pressures to $260 \mathrm{~kg} / \mathrm{cm}^{2}$, " Forschung auf dem Gebiete Ingenieurwesens, Vol. 5, pp. 138-145, 1934.

37. Koch, W., "The Heat of Vaporization of Water in the Pressure Range of 100 to $200 \mathrm{~kg} / \mathrm{cm}^{2}$," Forschung auf dem Gebiete des Ingenieurwesens, Vol.5, pp. 257-259. 1934. (Translated into English. School of Mechanical Engineering, Purdue University, 1960).

38. Koch, W., V.D.I., Wasserdampftafeln mit einem Mollier $(h, S)$ Diagramme, Springer Verlag, Berlin, Gottingen, Heidelberg, 1937.

39. Koch, W. and E. Schmidt, V.D.I. Wasserdampftafeln mit einem Mollier (h, S) Diagramme, Springer Verlag, Berlin, Gottingen, Heidelberg, 1952 . 
40. Leib, E. F。 Steam Tables, Combustion Engineering Inc., New York, N. Y., 1940 .

41. Leib, E.F. "Thermodynamic Properties of Vapours, "Transactions of the ASME, Vol.63, pp. 157-176, 1941.

42. Leib, E.F., "How the C-E Steam Tables Were Derived, Combustion, pp. 48-50 March 1941.

43. Moelwyn - Hughes, E.A., Physical Chemistry, Pergamon Press, New York, London, Paris, 1957.

44. Nowak, E.S. and R.J.Grosh, "An Investigation of Certain Thermodynamic and Transport Properties for Water and Water Vapor in the Critical Region:" Argonne National Laboratory Report ANL-6064, 1959.

45. Nowak, E。 S。, R。 J。Grosh, and P.E. Liley, "A Survey of P-V-T Data for Water in the Critical Region." Journal of Heat Transfer, Trans actions of the ASME, Vol.83, Series C, pp.1-13, 1961.

46. Nowak, E。S., R. J.Grosh, and P.E. Liley, "Smoothed Pressure Volume - Temperature Data for Water and Water Vapor in the Critical Region Derived from Experimental Measurements," Journal of Heat Transfer, Transactions of the ASME, Vol.83, Series C, pp. 14-27, 1961.

47. Nowak, E.S. and R.J.Grosh, "A Preliminary Development of a Rational Equation of State for Water and Water Vapor in the Critical Region," ASME Paper 61-H-79, accepted for Publication in Journal of Heat Transfer, September 1961.

48. Nowak, E, S., and R.J.Grosh, "The Coefficient of Volume Expansion for Water and Water Vapor in the Critical Region, "Argonne National Laboratory Report ANL-6404, August 1961.

49. Nowak, E。S. R.J.Grosh, An Analysis of Specific Heat Data Available for Water and Water Vapor in the Critical Region," Argonne National Laboratory Report ANL-6436, October 1961.

50. Osborne, N. S. "Calorimetry of a Fluid," Journal of Research of the National Bureau of Standards, Vol。4. pp.609-629, 1930.

51. Osborne, N.S. H. F. Stimson, and E. F. Fiock, "A Calorimetric Determination of Thermal Properties of Saturated Water and Steam from 0 to $270^{\circ} \mathrm{C}{ }^{18}$ Journal of Research of the National Bureau of Standards, Vol。5, pp. 411 = 480, 1930。

52. Osborne, N.S., H. F. Stimson, E.F.Fiock, and D.C.Ginnings, "The Pressure of Saturated Water in the Range 100 to $374^{\circ} \mathrm{C}$ " Journal of Research of the National Bureau of Standards, Vol.10, pp.155-188, 1933. 
53. Osborne, N. S., and C. H. Meyers, "A Formula and Tables for the Pressure of Saturated Water Vapor in the Range 0 to $374^{\circ} \mathrm{C}$," Journal of Research of the National Bureau of Standards, Vol. 13, pp. $1-20,1934$.

54. Osborne, N. S., H. F. Stimson, and D. C. Ginnings, "Calorimetric Determinations of the Thermodynamic Properties of Saturated Water in Both the Gaseous and Liquid States from 100 to $374^{\circ} \mathrm{C}$, " Journal of Research of the National Bureau of Standards, Vol.18, pp. 389-447, 1937 .

55. Osborne, N. S., H. F. Stimson, and D. C. Ginnings, "Measurements of Heat Capacity and Heat of Vaporization of Water in the Range 0 to $100^{\circ} \mathrm{C}$, J Journal of Research of the National Bureau of Standards. Vol. 23, pp. 197-260, 1939 .

56. Osborne, N. S., H. F. Stimson, and D. C. Ginnings, "Thermal Properties of Saturated Water and Steam," Journal of Research of the National Bureau of Standards, Vol. 23, pp. 261-270, 1939.

57. Riesenfeld, E. H. and T. L. Chang, "The Critical Data of Light and Heavy Water and the Density Temperature Diagram," Zeitschrift fur Physik, Series B, Vol. 30, pp.61-68, 1935.

58. Russkazov, D. S., and A. E. Sheindlin, "Experimental Investigations of the Specific Heat of Water and Water Vapor at High Parameters," Teploenergetika, Vol. 4, No. 11, pp. 81-83, 1957.

59. Schmidt, E., Thermodynamics, Principles and Applications to Engineering. (Translated into English by J. Kestin, Oxford at the Clarendon Press, 1949.)

60. Schmidt, E., V.D.I. Wasserdampftafeln mit einem Mollier (h, $S$ ) Diagramme bis $800^{\circ} \mathrm{C}$, Springer Verlag, Berlin, Gottingen, Heidelberg, 1956.

61. Sheindlin, A. E., "Experimental Investigations of Specific Heat, $\mathrm{C}_{\mathrm{p}}$, of Water and Water Vapor at High Parameters," Teploenergetika, Vol. 1, 1954.

62. Sirota, A. M., and B. K. Maltzev, "An Experimental Investigation into the Heat Capacity of Water at Temperatures from 10 to $500^{\circ} \mathrm{C}$ and Pressures up to $500 \mathrm{~kg} / \mathrm{cm}^{2}, "$ Teploenergetika, Vol. 6. No. 9 , pp. 7-15, 1959. (Translated into English, School of Mechanical Engineering, Purdue University, 1959).

63. Smith, L. B., F. G. Keyes, and H. T. Gerry, "Steam Research Program, Part II, The Vapor Pressure of Water, "Proceedings American Academy of Arts and Sciences, Vol. 69, pp.137-168, 1939.

64. Smith, L. B., and F. G. Keyes, "Steam Research Program, Part III, The Volumes of Unit Mass of Liquid Water and Their Correlation as a Function of Pressure and Temperature," Proceedings American Academy of Arts and Sciences, Vol. 69, pp. 285-312, 1934. 
65. Timrot, D. L., Tables of Thermodynamic Properties of Water and Water Vapor, First Edition, Moscow, Leningrad, 1952. (Translated into English by Land Turbine Engineering Division, Westinghouse Electric Corporation, South Philadelphia Works, November 1954)。

66. Timrot, D. L., S. L. Rivkin, A. M. Sirota, and N. B. Vargaftik, Tables of Thermodynamic Properties of Water and Water Vapor, Gosodarstvennoe Energetiskeskoe Izadelstvo, Second Edition, Moscow, Leningrad, 1958.

67. Timrot, D. L., "Heat Conductivity, Viscosity and Thermodynamic Properties of High Parameter Steam." (An article in a collection of papers entitled High Pressure Steam in Power Stations, State Power Publishing House, Moscow, 1950: English Translation available from Professor F. G. Keyes of Massachusetts Institute of Technology, Department of Chemistry\}).

68. Vukalovich, M. P., Thermodynamic Properties of Water and Water Vapor, Moscow 1951. (Translated into English by Large Steam Turbine Generator Department, General Electric Company, Schnectady, New York, September 1954).

69. Vukalovich, M. P., Thermodynamic Properties of Water and Water Vapor, State Scientific Technical Publication, Moscow 1955.

70. Vukalovich, M. P., Thermodynamic Properties of Water and Water Vapor, State Publishing House of Scientific Technical Literature Concerning Mechanical Engineering, Mashgig, Moscow, 1958.

71. Vukalovich, M.P.,A.E.Sheindlin, D.S.Russkazov, "Investigations of the Specific Heat, $\mathrm{C}_{p}$, of Water Vapor to $700 \mathrm{ATA}$ and $700^{\circ} \mathrm{C}$," Teploenergetika, Vol. 5, No.7, pp.7-9, 1958.

72. Wentorf, R. H. and C.A.Boyd, "Isotherms in the Critical Regions of Carbon Dioxide and Sulphur Hexaflouride," University of Wisconsin Naval Research Laboratory, Department of Chemistry, Report CM 724, 1952. 